\title{
Hourly-resolution analysis of electricity decarbonization in Spain (2017-2030)
}

\author{
Marta Victoria , Cristobal Gallego-Castillo
}

H I G H L I G H T S

Keywords:

Energy modeling

Energy analysis

$100 \%$ renewable power system

Renewable grid integration

Time series analysis

Spain

\begin{abstract}
A B S T R A C T
Two alternative paths to achieve highly-renewable electricity generation in peninsular Spain are investigated in this paper. Every transition path comprises a description of the installed and decommissioned generation and storage capacities, from 2017 to 2030 , as well as a hypothesis on the evolution of the electricity demand. The electricity mix for every hour within the transition path is determined through a dispatch algorithm that prioritizes electricity from renewable energy sources. The simulation is run for 900 different combinations of time series representing the hourly capacity factors of different technologies, as well as the electricity demand. This robust approach allows the evaluation of the transition paths based on the statistical distribution of several defined assessment criteria, such as security of supply, $\mathrm{CO}_{2}$ emissions or renewable share in electricity generation. The feasibility of a Spanish power system with high renewable penetration is investigated not only in a future reference year but throughout the transition path. In particular, a progressive and simultaneous phase-out of nuclear and coal power plants in the short-term is proven to be feasible. Furthermore, the results sensitivity is analyzed including scenarios with a delayed nuclear phase-out, lower hydroelectricity generation due to more frequent and severe droughts caused by climate change and higher annual increment for the electricity demand.
\end{abstract}

\section{Introduction}

Since the energy sector is the main emitter of greenhouse gases, a profound transformation of the global energy system is mandatory to mitigate climate change. Avoiding global average temperature to rise above $2^{\circ} \mathrm{C}$ requires achieving almost zero carbon emissions from electricity generation worldwide by 2050 [1]. Several fundamental questions arise when approaching this problem: What is the best combination of Renewable Energy Sources (RES) to achieve a fully renewable electricity mix? How much backup and storage capacities would be needed to counterbalance RES variability? Which could be the role of interconnections with other sectors or among adjacent countries? And, in summary, what is the best strategy to achieve a timely zero-carbon-emission electricity generation to avoid a catastrophic temperature increment?

Several modeling approaches have been proposed to assess the feasibility of power systems with high renewable penetration at different regional scales: global [2-4], Europe [5-7], USA [8], Denmark [9], Australia [10], New Zealand [11], Portugal [12], France [13], Ireland [14], Germany [15], or the Nordic region [16]. Table 1 summarizes the main characteristics of those models. We restrict the table to previous works dealing with highly-renewable power systems, although there are also several papers which analyze how to supply the whole final energy consumption of a certain region by using only RES 
Table 1

Previous works analyzing the feasibility of power systems with high RES penetration in different regions.

\begin{tabular}{|c|c|c|c|c|c|c|}
\hline Authors & Region & Spatial resolution & Time series & Scenario where results are simulated & Time-step & Aim \\
\hline Rasmussen et al. [27] & Europe & One node & $8(2000-2007)$ & No time reference & $1 \mathrm{~h}$ & Least-cost solution \\
\hline Eriksen et al. [6] & Europe & One-node-per-country network & $8(2000-2007)$ & No time reference & $1 \mathrm{~h}$ & Least-cost solution \\
\hline Schlachtberger et al. [7] & Europe & One-node-per-country network & $1(2011)$ & $95 \% \mathrm{CO}_{2}$ abatement & $1 \mathrm{~h}$ & Least-cost solution \\
\hline Schlachtberger et al. [49] & Europe & One-node-per-country network & $4(2011-2014)$ & $95 \% \mathrm{CO}_{2}$ abatement & $1 \mathrm{~h}$ & Least-cost solution \\
\hline Brown et al. [50] & Europe & One-node-per-country network & $1(2011)$ & $95 \% \mathrm{CO}_{2}$ abatement & $1 \mathrm{~h}$ & Least-cost solution \\
\hline Collins et al. [28] & Europe & One-node-per-country network & $30(1985-2014)$ & 5 reference scenarios (2030) & $1 \mathrm{~h}$ & Scenario comparison \\
\hline Gils et al. [51] & Europe & 15 regions & 1 & No time reference & $1 \mathrm{~h}$ & Least-cost solution \\
\hline Brancucci et al. [5] & Europe & One-node-per-country network & $1(2010)$ & 2025 & $1 \mathrm{~h}$ & \\
\hline Connolly et al. [52] & Europe & One node & 1 & 2050 & $1 \mathrm{~h}$ & Scenario comparison \\
\hline Lund and Mathiesen [9] & Denmark & One node & 1 & 2030 and 2050 & $1 \mathrm{~h}$ & Scenario comparison \\
\hline Krajaçić et al. [12] & Portugal & One node & $1(2006)$ & 2020 & $1 \mathrm{~h}$ & Supply-demand check \\
\hline Elliston et al. [10] & Australia & One node & $1(2010)$ & Present $(2010)$ & $1 \mathrm{~h}$ & Supply-demand check \\
\hline Mason et al. [11] & New Zealand & One node & $3(2005-2007)$ & Present (2005-2007) & $30 \mathrm{~min}$ & Supply-demand check \\
\hline Olauson et al. [16] & Nordic Region & One node & 3 & Present & $1 \mathrm{~h}$ & \\
\hline ADEME [13] & France & 21 regions & & 2050 & $1 \mathrm{~h}$ & \\
\hline Greenpeace [20] & Spain & One node & $1(2005)$ & 2050 & $1 \mathrm{~h}$ & Least-cost solution \\
\hline Galbete [21] & Spain & One node & 10 & No time reference & $1 \mathrm{~h}$ & Supply-demand check \\
\hline Zubi et al. [22] & Spain & One node & $2(2007)$ & Present & $1 \mathrm{~h}$ & Supply-demand check \\
\hline
\end{tabular}

[17-19]. The works included in Table 1 try to achieve one or both of the following objectives. First, some authors focus on ascertaining that a certain RES capacities mix is able to supply hourly the inelastic demand for one or several future reference years. Second, others optimize a constrained system, that is, they determine the least-cost solution to attain $100 \%$ renewable electricity or a certain $\mathrm{CO}_{2}$ emissions reduction target.

The present work focuses on the Spanish power system and investigates not only the feasibility of future highly-renewable scenarios but also the main challenges throughout the transition period. To do that, we use a simplified dispatch algorithm to simulate the hourly electricity mix for every year between 2017 and 2030. The significance of analyzing the Spanish case is twofold:

1. Only a few previous works considering the case study of Spain exist [20-22]. We describe in Section 2 how our approach overcomes some of their limitations. Moreover, we should remark that the importance of analyses at the national level relies on the fact that renewable and local resources show high regional dependence [23], meaning that optimal RES mixes are likely to differ notably from one country to another.

2. The low interconnection capacity to the rest of the European synchronous network makes the system quasi-isolated. Hence, challenges arise for lower renewable penetration values and alternative approaches to deal with them can be tested in advance and extrapolated to other regions.

Available literature on the modeling of the Spanish power system is sparse. Greenpeace has published three different reports on the Spanish energy transition. In the first one [24], the potential for renewable energy generation is estimated for every technology, showing that it will be more than enough to cover electricity demand in 2050. In the second report [20], the technical feasibility of $100 \%$ renewable power system in 2050 is performed. The analysis is based on one-year time series obtained by aggregating the generation time series of simulated power plants installed in several Spanish regions. The capacities mix is optimized according to different criteria and, in all cases, Concentrated Solar Power (CSP) hybridized with biomass has a prominent role thanks to its partial dispatchability. The third report by Greenpeace [18] describes a possible technology mix to supply the final energy consumption using only RES. The thesis by S. Galbete [21] also evaluates the transition towards 100\% renewable electricity generation in Spain. In this case, instead of using a temporal reference, the ratio between the potentially generated renewable energy and the annual electricity demand is the parameter varied throughout the transition. The methodology followed by S. Galbete to obtain RES time series is also based on the aggregation of generation of power plants installed in different regions. Put it simply, S. Galbete has access to historical generation time series for individual wind and photovoltaic (PV) power plants. He assumes that those time series represent the wind/solar generation pattern of the region where they are installed and aggregates the time series for all the individual sites available, weighted by the power capacity installed in every region, to obtain the hourly capacity factor time series for Spain. Although time series corresponding to ten years are derived, the analysis is mostly performed using data from only one year. Thomaidis et al. [25] follow a portfoliobased approach to investigate the distribution of wind and CSP capacities in southern Spain that maximizes the energy harvested through the year while minimizing the variability of renewable generation (quantified by means of the standard deviation of the aggregate wind and CSP capacity factors). Finally, the last two references worth mentioning investigate the best renewable technology mix for different regions including Spain. Jacobson and his coauthors [19] calculate the optimal energy mix for Spain in 2050 while Breyer and coauthors [26] optimize the generation capacities mix for the whole Iberian Peninsula in 2030. The outcomes of our model are compared to theirs in Section 4.1.

As previously mentioned, several authors have analyzed the feasibility of highly-renewable power systems for different regions using as input time series for one single year $[7,9,10]$, 3 years $[11,16]$, 8 years $[6,27]$ or up to 30 years [28]. See Table 1 for a general outlook. The first significant innovation of this paper is the methodological approach which involves analyzing the correlation of available historical generation, demand, and hydro inflow time series, as well as combining and using these time series to simulate the Spanish power system with high renewable penetration. The selection strategy applied to obtain 900 time series combinations ${ }^{1}$ ensures that year-to-year variability is retained and avoids that results are influenced by the particular weather conditions of one year. This also allows the evaluation of the transition paths using statistical assessments of different criteria such as security of supply, $\mathrm{CO}_{2}$ emissions or renewable generation share. Furthermore, among the time series combinations some are particularly stringent, e.g., severely drought-impacted hydroelectric output in

\footnotetext{
${ }^{1}$ The 900 combinations are obtained by combining 6 hourly capacity factors for wind (and coal, linked with wind), 5 hourly capacity factor for nuclear, 5 time series for hydro inflow, 3 time series for electricity demand, 2 hourly capacity factors for photovoltaics, and 1 hourly capacity factor time series for CSP, cogeneration, biomass and small-hydro. They are shown in Table 2 in Supplementary Materials.
} 
Table 2

List of symbols.

\begin{tabular}{ll}
\hline Name & Description \\
\hline$C_{h}^{t, y}$ & Cumulative installed capacity of technology $t$ at hour $h$ of year $y$ \\
$C^{k, g e n / s t o}$ & Generation/pumping capacity, $k=$ CON, PHS, or MIX for \\
& Conventional, pure-pumping-store, and mixed hydroelectric power \\
& plants \\
$C F_{h}^{t, y}$ & Capacity factor of technology $t$ at hour $h$ of year $y$ \\
$C R_{h}$ & Coverage ratio at hour $h$ \\
$C_{i}$ & Correlation index \\
$D_{h}^{y}$ & Demand at hour $h$ of year $y$ \\
$\widehat{D}_{h}^{y}$ & Demand at hour $h$ of year $y$ normalized using average demand \\
$D_{a v e}^{y}$ & Average demand for year $y$ \\
$e_{h}^{k}$ & Filling level of hydroelectric stores at hour $h$ \\
$e^{k, m a x / m i n}$ & Max/min filling level of hydroelectric stores \\
$E_{h}^{d i s p}$ & Dispatchable energy generated at hour $h$ \\
$E_{h}^{n o n-d i s p}$ & Non dispatchable energy generated at hour $h$ \\
$E_{h}^{t, y}$ & Energy generated by technology $t$ at hour $h$ of year $y$ \\
$h$ & Hour \\
$i n_{h}^{y}$ & Hydro inflow at hour $h$ of year $y$ \\
$j$ & Ensemble of time series \\
$N_{c h}$ & Number of critical hours \\
$N_{t}$ & Number of years with historical data for technology $t$ \\
$y$ & Year, historical \\
$y^{*}$ & Year, belonging to transition path \\
$\eta_{S}$ & Round-cycle hydro storage efficiency \\
$\rho_{Y, Z}$ & Correlation coefficient for time series Y and Z \\
$\sigma_{Y}$ & Standard deviation for time series Y \\
\hline & \\
&
\end{tabular}

winter combined with coincident low PV and wind output. Such demanding scenarios will become more common as climate change increases the probability of occurrence of extreme weather phenomena. Including them in the analysis is one of the feasibility criteria lacking in most studies [29].

The second significant novelty of this paper is the fact that, for the first time, the role of PV has been seriously considered as one of the central technologies to decarbonize the Spanish electricity system. Most of the aforementioned works devoted to the analysis of Spain relay heavily on wind, biomass, and CSP, predicting a small share of PV. However, since PV has experienced such a dramatic cost decrease in the last decade, its role in future scenarios has been notably underestimated in the past $[26,30]$. In this work, we consider high PV penetration and present a novel methodology to obtain hourly time series representative for PV in Spain where no historical data is available for this technology.

Finally, while most of the works in Table 1 focus on evaluating the possible scenarios at present year $[10,11,16]$, for one (2020 in [12], 2030 in [26]), two (2030 and 2050 in [9]) or up to six reference years in the future (2050-2055 in [8]), our work expands the modeling to every year from 2017 to 2030 allowing the analysis of the most significant challenges that will arise throughout the transition.

The paper is organized as follows. Section 2 includes the methods description. The methodology to obtain the hourly capacity factors for various technologies and the hourly electricity demand is described in Sections 2.1 and 2.2. The procedure to select the time series that comprise the 900 combinations used to evaluate the system is shown in Section 2.3. Section 2.4 provides information regarding hydroelectricity power plants in Spain and Section 2.5 details the dispatch algorithm to supply the electricity demand every hour. The last methods subsection, that is 2.6 , includes the description of the assessment criteria. Section 3 provides the description of the two alternative transition paths that have been investigated. Section 4 includes results and discussion. A critical appraisal is included in Section 5 where the main limitations of the model and their implications are discussed. Finally, the conclusions are highlighted in Section 6.

\section{Methods}

Fig. 1 shows a general scheme of the methodology used in this paper. First, the hourly capacity factors ${ }^{2}$ for different technologies and electricity demand are obtained by computing the ratio between the historical generation time series provided by REE (the Spanish Transmission System Operator, TSO) and the cumulative installed capacity. Based on the correlation analysis among available time series, some of them are selected and 900 combinations are assembled. Second, the characteristics of the transition path under analysis are set. Every transition path represents a combination of assumptions, including the installed and decommissioned capacity for every generation and storage technology, as well as a hypothesis on the evolution of the electricity demand. Third, the dispatch algorithm is applied to determine the hourly electricity mix throughout the analyzed period (2017-2030). This step is repeated 900 times using the different time series combinations. Finally, the evaluation of every transition path is performed based on the statistical distributions of the assessment criteria (security of supply, $\mathrm{CO}_{2}$ emissions, RES share of electricity production, etc.). The model is implemented in Python which is an open-source interpreted programing language. On a standard 2014-desktop PC, the simulation of a transition path (2017-2030) with a time step of $1 \mathrm{~h}$ and including 900 time series combinations takes about $14 \mathrm{~h}$.

\subsection{Hourly capacity factors for different technologies}

The hourly capacity factors of each technology vary from year to year. Wind and solar generation time series are determined by local weather, hydroelectric output depends on rainfall patterns, nuclear available capacity is modified by scheduled maintenance outages as well as unscheduled shutdowns, etc. Rather than artificially producing hourly capacity factors for every technology, our approach is based on obtaining those time series from actual historical data. ${ }^{3}$ This information is provided by REE [31].

For every technology $t$ and historical year $y$, the hourly capacity factor $C F_{h}^{t, y}$ for every hour $h$ is calculated by dividing the electricity generated by that technology $E_{h}^{t, y}$, by the cumulative installed capacity in that hour $C_{h}^{t, y}$.

$C F_{h}^{t, y}=\frac{E_{h}^{t, y}}{C_{h}^{t, y}}$

REE provides the cumulative installed capacities on December 31st of every year. The installation and decommissioning of new power plants are assumed to occur linearly throughout the year. Thus, the capacity at hour $h$ is estimated as

$C_{h}^{t, y}=C_{8760}^{t, y-1}+\frac{h}{8760}\left(C_{8760}^{t, y}-C_{8760}^{t, y-1}\right)$

where $C_{8760}^{t, y}$ represents the cumulative installed capacity at the end of year $y$. This method is used to calculate hourly capacity factors for several historical years and technologies (nuclear, coal, small hydroelectric, CSP, wind, and cogeneration ${ }^{4}$ ). For PV, due to the lack of historical data, hourly capacity factors are obtained following a different approach described in Section 2.2 .

An important assumption in this work is that, for the case of large hydroelectric, gas, and biomass the maximum capacity factor assumed

\footnotetext{
${ }^{2}$ We define hourly capacity factor, for every hour in a year, as the hourly time series comprising the ratio between the energy produced by a certain technology in that hour and the energy that would have been produced operating at the rated power, i.e., the installed capacity.

${ }^{3}$ The authors are willing to share all the time series used across this paper to anyone who wishes to replicate the results of this study.

${ }^{4}$ Cogeneration represents the electricity produced in the industry by using a heat engine or power station to generate electricity and useful heat at the same time. It is also known as Combined Heat and Power (CHP).
} 


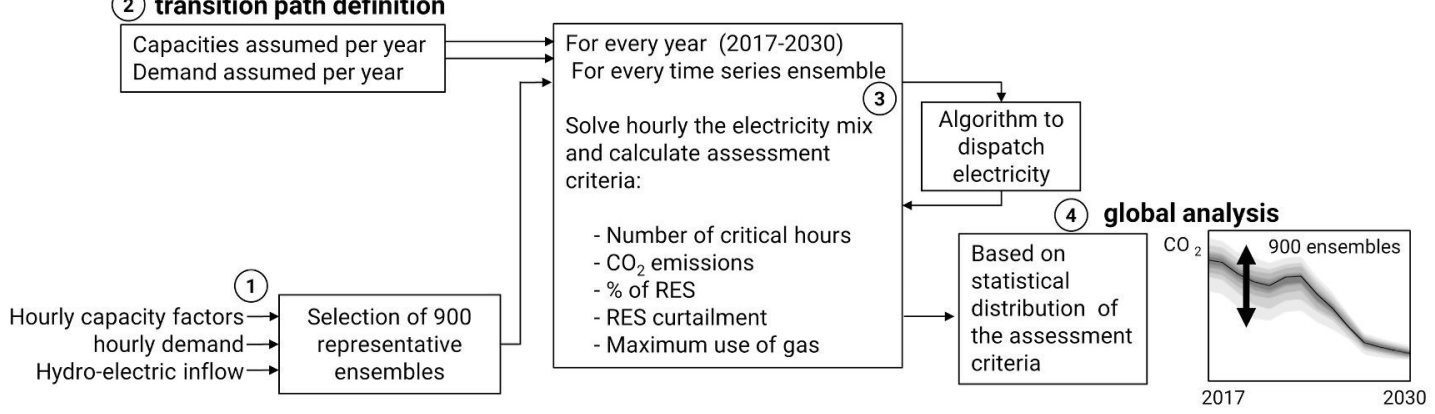

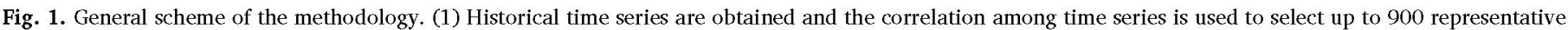

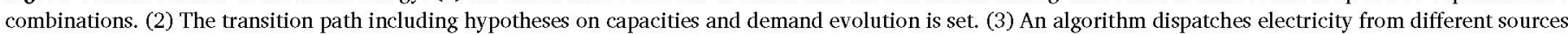

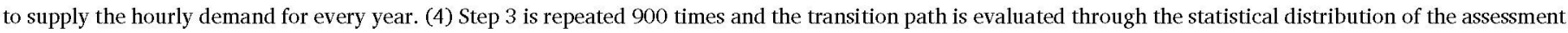
criteria.

for every hour is 1 .

$C_{h}^{t, y} \leqslant 1, \quad$ for $t \in$ [large hydro, gas, biomass]

For the sake of conciseness, the additional assumptions made when processing the data provided by REE to obtain the hourly capacity factors are described in the Supplementary Materials.

Regarding hourly capacity factors for wind energy, it must be remarked here that the current modeling approach (in which capacity factors derived from historical generation time series are used to simulate future performance) is extremely conservative. As the technology develops and enhanced power curves for wind turbines are obtained, a significant increment in wind capacity factors is predicted [32]. The expected gain will be even more pronounced if part of the future wind capacity is installed offshore.

REE provides time-resolved demand time series $D_{h}^{y}$, that are normalized here using the average hourly demand in the year $D_{\text {ave }}^{y}$

$\widehat{D}_{h}^{y}=\frac{D_{h}^{y}}{D_{a v e}^{y}}$

The historical demand time series have been shifted the necessary days so that all of them starts on Monday and the weekly consumption pattern is retained.

Finally, the hydroelectric inflow in ${ }_{h}^{y}$, i.e., the amount of water, expressed in energy units, that due to rainfall is stored in reservoirs, is reported by REE with monthly resolution. It has been assumed that the hydroelectric inflow is evenly produced such that a constant value is considered for every hour within the same month. Fig. 2 depicts some of the time series corresponding to 2014 .

\subsection{Hourly capacity factors for photovoltaics}

The method described in the previous section is not suitable to obtain PV hourly capacity factors. The reason is that REE reports the total electricity production with solar origin, i.e., without splitting apart that produced in CSP power plants and that based on PV. Consequently, the aggregate solar hourly capacity factor cannot be used to represent PV generation in Spain since values different from zero are observed at night (due to the dispatchability of part of the CSP installed capacity). Furthermore, in as much as PV is key in the transition paths under analysis, a proper calculation of hourly capacity factors for this technology is needed.

Our approach consists in using solar radiation measurements at ground stations and a simulation software to estimate PV hourly capacity factors that are representative for peninsular Spain. Besides solar irradiance, ambient temperature, system configuration (orientation, inclination, stationary or tracking), and efficiencies of the inverter and voltage conversion impact on the generated electricity. Moreover, the number of PV plants considered and their locations could also affect the hourly time series and their variability.

In this case, 35 representative PV installations located across peninsular Spain are considered. Their locations are shown in Fig. 3. For every representative installation, and for every year within the period 2010-2015, the hourly-resolved Global Horizontal Irradiance (GHI) is obtained from the corresponding ground station within the SIAR network. SIAR is the acronym, in Spanish, of the Acro-climatic Information System for Irrigation, which belongs to the Spanish Ministry of Agriculture and Fisheries, Food and Environment [33]. Based on the GHI and the ambient temperature, the hourly capacity factors are obtained by means of SISIFO, the online, free-software, simulator for grid-connected PV systems developed by the Technical University of Madrid $[34,35]$. The solar conversion process can be summarized as follows. First, the clearness index is computed and GHI is decomposed in direct and diffuse irradiance on the horizontal plane. Second, direct, diffuse, and albedo irradiances on a tilted surface are calculated. Third, the PV module temperature and its impact on the conversion efficiency are estimated. Fourth, the wiring losses, inverter efficiency, and voltage conversion efficiency are included and data from the 35 locations are aggregated to obtain hourly capacity factors representative for Spain. Finally, the resulting time series is corrected in such a way that the annual capacity factor for every year matches the actual historical figure for that particular year. Details on the correction procedure are provided in the Supplementary Materials. For every location, static, flat silicon PV panels with optimum inclination and orientation, together with standard components for the rest of the system, are assumed.

Fig. 4 depicts the average and dispersion of the annual capacity factors calculated for the different locations. We could have made alternative hypotheses such as different locations for the PV plants or a non-uniform capacity distribution assuming, for instance, that PV plants are likely installed in places with high irradiance. However, we believe that this coarse mesh is sufficient to obtain a proper representation of the global PV generation in Spain.

\subsection{Selection of representative time series combinations}

Using the methodology described in Sections 2.1 and 2.2, several hourly capacity factors ${ }^{5}$ are obtained for some of the generation technologies as well as hourly time series for electricity demand and hydroelectric inflow. The annually integrated values for every hourly capacity factors and inflow time series are shown in Fig. 5. The number of different combinations that could be generated using the available time series $\left(6^{5} \cdot 25\right)$ would lead to unbearable computational time.

\footnotetext{
${ }^{5} 6$ hourly capacity factors time series are available for nuclear, coal, wind, and photovoltaics; 6 time series for electricity demand; 25 time series for hydro inflow and 1 hourly capacity factor time series for CSP, cogeneration, biomass, and small-hydro are also available.
} 

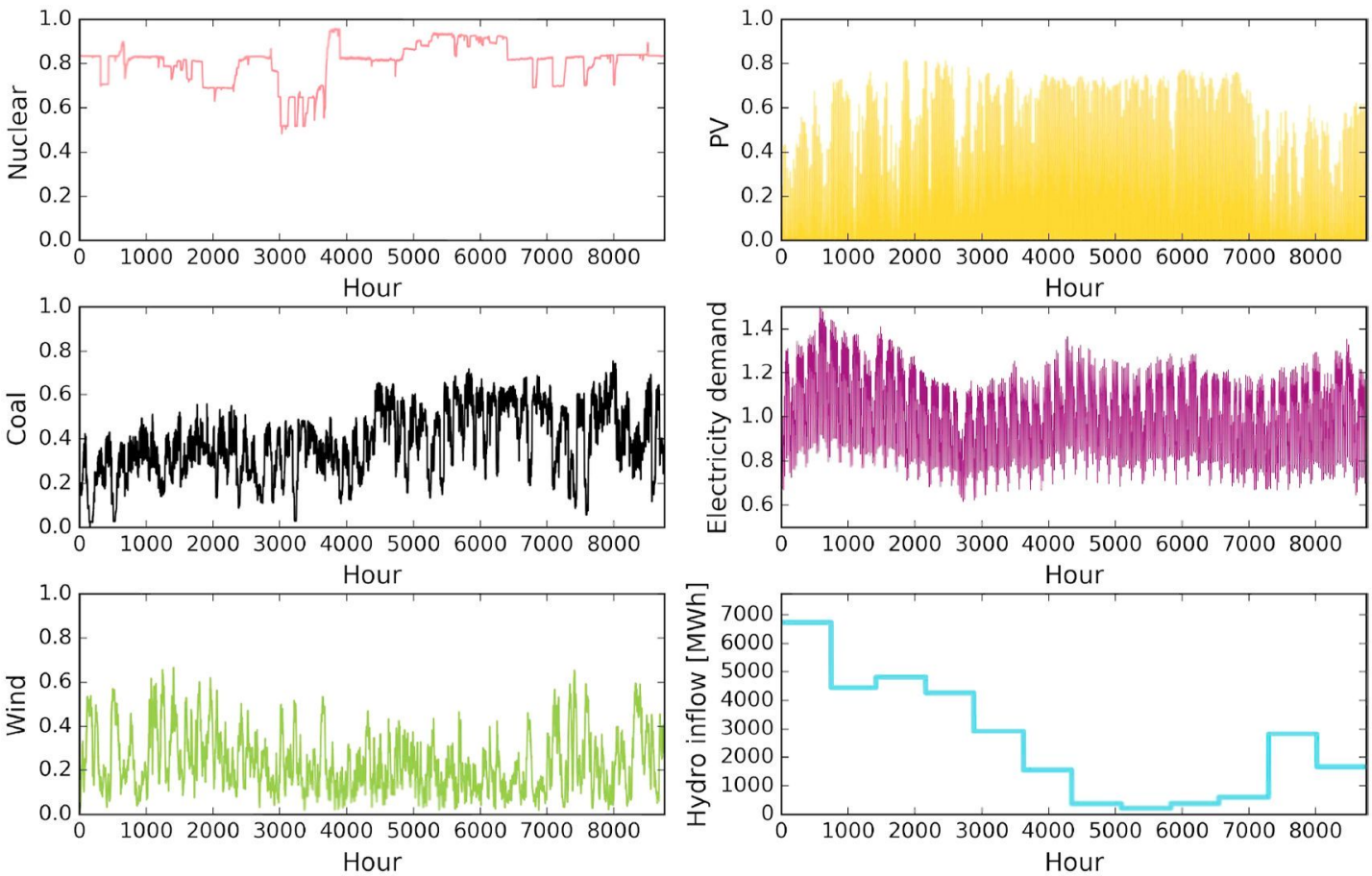

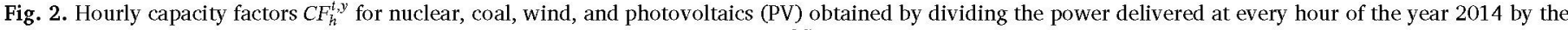
cumulative installed capacity. Country-aggregate normalized electricity demand $\widehat{D}_{h}^{y}$ and hydroelectric inflow time series in ${ }_{h}^{y}$ are also shown for the same year.

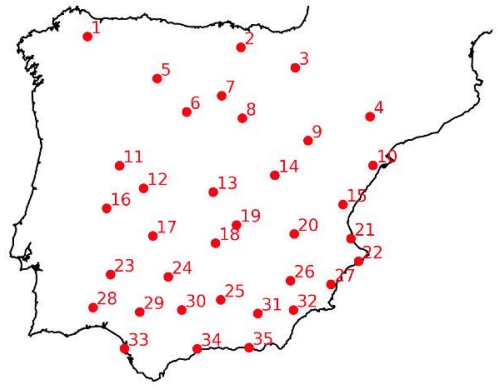

Fig. 3. Locations assumed for PV plants.

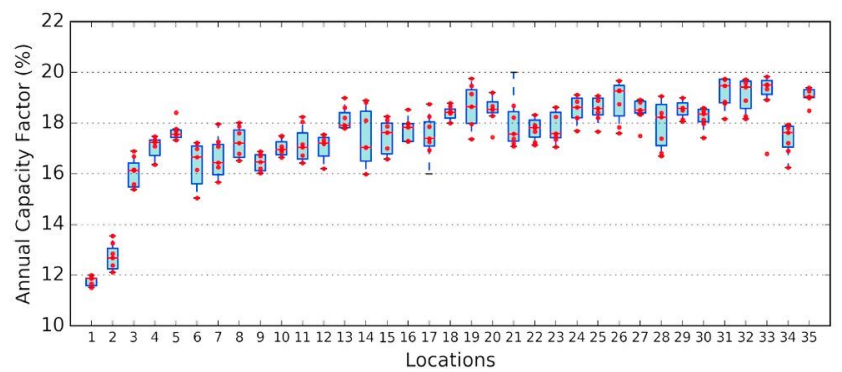

Fig. 4. Annual capacity factors for the assumed PV power plants locations (shown in Fig. 3).

Hence, only some of the time series (indicated with red circles in Fig. 5) are selected to create a total of 900 combinations used in the simulations. The historical years corresponding to the selected hourly capacity factors for every technology are indicated in the Supplementary Materials.

To select among the available time series, the criteria are to select firstly the most representative year (the most correlated with the available years), and then to include those years that show the lower correlation with the one already selected. To this end, a correlation analysis is carried out for every technology separately. For every

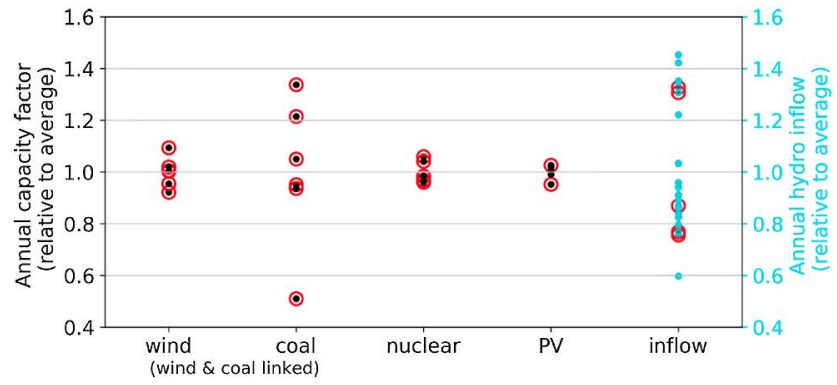

Fig. 5. Annual capacity factors for different technologies. Normalized values (relative to average) are shown. The right y-axis indicates the annual hydro inflow, also in relative values. Black and blue dots represent time series obtained by processing historical data from REE. Red circles indicate those time series that have been selected through the correlation analysis and used to create the 900 time series combinations. The demand time series are not included in this figure since all of them have been normalized so that the average value is one. (For interpretation of the references to color in this figure legend, the reader is referred to the web version of this article.)

technology, the Pearson's correlation coefficient $\rho_{Y, Z}$ for two years $Y$ and $Z$ is calculated as

$\rho_{Y, Z}=\frac{\operatorname{Cov}(Y, Z)}{\sigma_{Y} \sigma_{Z}}$

where $\operatorname{Cov}$ is the covariance and $\sigma_{Y}$ and $\sigma_{Z}$ the standard deviation of time series for the years $Y$ and $Z$. For instance, Fig. 6 depicts the correlation matrix for nuclear, that is $\rho_{Y, Z}$ for all the years in which historical data is available for this technology. This technology can be used to illustrate the procedure. First, the correlation coefficients in the matrix are summed along the vertical (summing along the horizontal would be equivalent since the matrix is symmetric), and the year $Y_{1}$ of the column with the largest sum is selected.

$\sum_{j=1}^{N_{t}}\left|\rho_{Y_{1}, j}\right|=\max _{i}\left\{\sum_{j=1}^{N_{i}}\left|\rho_{i, j}\right|\right\}$ 


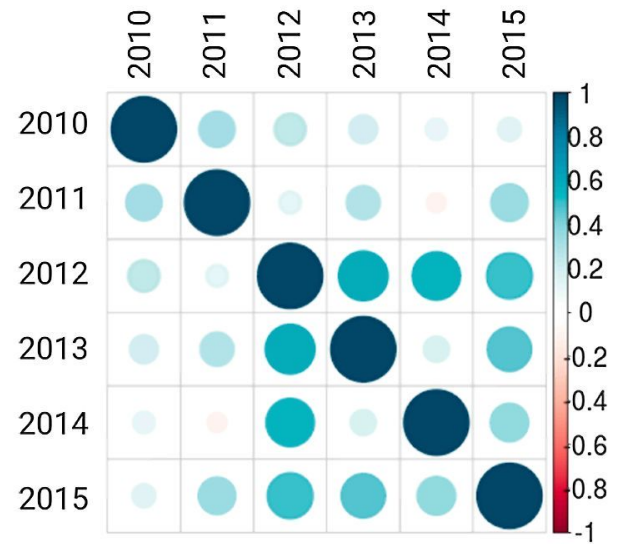

Fig. 6. Correlation coefficients $\rho_{X, Y}$ for nuclear hourly capacity factors.

where $N_{t}$ is the number of years for which historical data is available for technology $t$. The mean of the absolute correlation coefficients for the year $Y_{1}$ is defined as the first correlation index $C_{1}$.

$C_{1}=\underset{j}{\operatorname{mean}}\left\{\left|\rho_{Y_{1}, j}\right|\right\}$

This ensures that the hourly capacity factor most similar to the remaining 5 time series, i.e., the most representative, is selected. For nuclear, this corresponds to $Y_{1}=2012$. Second, we chose the hourly capacity factor for the year $Y_{2}$ with the lowest correlation with the first selected year, i.e., the year most different to the one already selected, and hence, the one adding largest variability.

$\left|\rho_{Y_{1}, Y_{2}}\right|=\min _{j}\left\{\left|\rho_{Y_{1}, j}\right|\right\}$

For nuclear this corresponds to $Y_{2}=2011$. The correlation index $C_{2}$ is calculated as the absolute value of the Pearson's correlation coefficient between $Y_{1}$ and $Y_{2}$, for the case of nuclear 2012 and 2011.

$C_{2}=\left|\rho_{Y_{1}, Y_{2}}\right|$

Third, we chose the hourly capacity factor for the year $Y_{3}$ most different to the first and second selections, which, in this case, corresponds to 2010 .

$\left|\rho_{Y_{1}, Y_{3}}\right|+\left|\rho_{Y_{2}, Y_{3}}\right|=\min _{j}\left\{\left|\rho_{Y_{1}, j}\right|+\left|\rho_{Y_{2}, j}\right|\right\}$

Correlation index $C_{3}$ is calculated as the average of the absolute values of the correlation coefficients of $Y_{3}$ with $Y_{1}$ and $Y_{2}$.

$C_{3}=\frac{\left|\rho_{Y_{1}, Y_{3}}\right|+\left|\rho_{Y_{2}, Y_{3}}\right|}{2}$

This process is repeated until all the available time series are sorted according to their selection priority.

Fig. 7 depicts the correlation indices $\left(C_{1}, C_{2}, C_{3} \ldots\right)$ for different technologies. Significant insights can be derived from that figure. Firstly, year-to-year variability for PV hourly capacity factors is much lower than that of wind time series. Secondly, the high correlation of electricity demand time series is intuitive since aggregate demand is heavily influenced by daily and weekly patterns. Thirdly, it may seem counter-intuitive the low correlation of nuclear hourly capacity factors since the nuclear output is thought to be constant throughout the year. However, the planned stops to recharge uranium in the power plants, as well as unexpected shutdowns, introduce sudden changes (in the order of hundreds of megawatts per minute) in the nuclear time series. The possible correlation between time series of different technologies has also been carefully analyzed. The global correlation matrix including all the technologies is provided in the Supplementary Materials. The only correlation that can be clearly appreciated is the strong negative correlation between coal and wind time series. This is a direct consequence

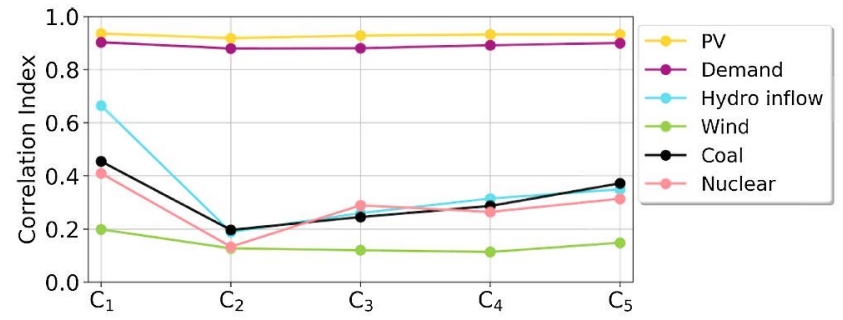

Fig. 7. For every technology, the correlation indices $C_{i}$, as defined in the text, are shown.

of the historical role that coal has played as a backup technology for time periods with low wind generation. Consequently, the time series of coal has been linked to that of wind, meaning that when combining time series, hourly capacity factors derived from the same historical year for coal and wind are included in each combination.

Based on the correlation analysis, a higher number of time series is selected for those technologies showing larger year-to-year variability. To include significant variability and keep computation time feasibly, 900 time series combinations are created. It is found that the normalized standard deviation of the results is stable when using such a large number of simulations. Furthermore, the selection procedure is found to be better than an alternative methodology, such as randomly combining time series from different technologies. More information is provided in the Supplementary Materials. It should be noted here that, among the time series combinations, some of them are particularly stringent. For instance, one of the combinations includes wind, nuclear, $\mathrm{PV}$, and inflow time series whose relative annually integrated values are respectively $92 \%, 96 \%, 95 \%$, and $76 \%$ of the historical average values (see Fig. 5). This represents a very demanding scenario due to the coincidence of weather characteristics that simultaneously reduce output from every RES. Although this may not be realistic for todays weather, it could be useful to represent future scenarios in which, as a result of climate change, extreme weather events are likely to occur.

An additional remark regarding hydro inflow time series is also worth to be made. The year with the lowest annual hydro inflow shown in Fig. 5 corresponds to 2005 when annual inflow was only $60 \%$ of 25 years average. When applying the previously described method, hydro inflow time series corresponding to 2005 does not get selected to become part of some of the 900 combinations. The analyses of the transition paths described in Section 4 were repeated including 2005 hydro inflow time series with negligible differences in the results. When carefully analyzing the historical hydro-inflow time series it is observed that those corresponding to other years, such as 2007 , are more challenging. The reason is that, although annual hydro inflow is lower for 2005, the year 2007 includes the longest succession of dry months (with very low hydro inflow) limiting the hydroelectricity generation during those months. A figure comparing hydro inflow time series in 2005 and 2007 is provided in the Supplementary Materials.

\subsection{Hydroelectric power plants and reservoirs}

Table 3 summarizes the characteristics of the hydroelectric power plants in peninsular Spain in 2016. They are assumed to remain constant throughout the transition paths analyzed in Section 4. Three kinds of hydroelectric power plants are considered. The adjective conventional is used for those power plants connected to irreversible storage. They use a dam to store river water in a reservoir and release it to generate electricity. The pure-pumped-storage power plants (PHS) store energy by pumping water uphill to a reservoir at a higher altitude from a second reservoir at a lower elevation. The mixed-storage power plants are usually installed between two consecutive reservoirs at different altitude with river inflow. In principle, the operation of mixed-storage power plants depends on the season. In dry seasons, low river inflow is 
Table 3

Storage, generation, and pump capacities for the different kinds of hydroelectric power plants in peninsular Spain in 2016.

\begin{tabular}{|c|c|c|c|c|c|}
\hline & $\begin{array}{l}\text { Generation capacity } \\
\text { (MW) }\end{array}$ & $\begin{array}{l}\text { Pump capacity } \\
\text { (MW) }\end{array}$ & $\begin{array}{l}\text { Storage capacity } \\
\text { (GWh) }\end{array}$ & $\begin{array}{l}\text { Minimum filling } \\
\text { level, } e^{\text {min }}\end{array}$ & $\begin{array}{l}\text { Maximum filling level, } \\
e^{\max }\end{array}$ \\
\hline $\begin{array}{l}\text { Conventional hydroelectric power plants (irreversible } \\
\text { storage) }\end{array}$ & 12,700 & 0 & 16,500 & $30 \%{ }^{\mathrm{e}}(20 \%)$ & $78 \%{ }^{\mathrm{e}}$ \\
\hline $\begin{array}{l}\text { Mixed-storage hydroelectric power plants } \\
\text { (conventional + pumped storage) }\end{array}$ & $2200^{\mathrm{b}}$ & $2200^{\mathrm{b}}$ & $2000^{\mathrm{d}}$ & $30 \%{ }^{\mathrm{e}}\left(20 \%{ }^{\mathrm{f}}\right)$ & $78 \%{ }^{\mathrm{e}}$ \\
\hline Pumped-storage hydroelectric power plants & $3300^{\mathrm{a}}$ & $3500^{\mathbf{a}}$ & $73^{d}$ & $0 \%{ }^{\mathrm{e}}$ & $100 \%$ \\
\hline Small hydroelectric power plants & $2100^{\mathrm{a}}$ & & & & \\
\hline TOTAL & $20,300^{\mathbf{a}}$ & 5700 & $18,500^{\mathrm{c}}$ & & \\
\hline
\end{tabular}

a Total, small-hydro, and pump capacities are annually reported by REE [31].

b The aggregate capacity for mixed hydroelectric power plants is reported in [21].

c The total storage capacity for all the reservoirs in Spain $(18,500 \mathrm{GWh})$ is included in the monthly report by REE [31].

d The capacity of reservoirs associated with pumped storage and mixed hydroelectric power plants is reported in [21]. For reservoirs associated with mixed

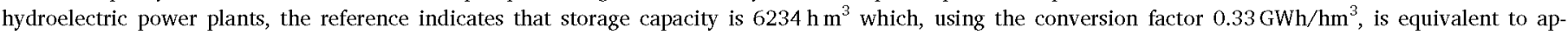
proximately $2000 \mathrm{GWh}$.

e The minimum and maximum filling level of the different reservoirs is chosen to reproduce the historical minimum values which are monthly reported by REE

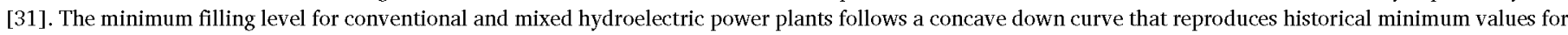

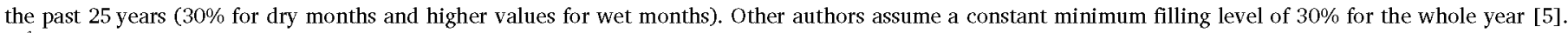

$\mathrm{f}$ In the case that, for a certain hour, available generation is lower than demand, the minimum filling level is reduced to $20 \%$ (only for that particular hour).

filling the reservoirs and they work as pure-pumped-storage power plants. In wet seasons, they operate as conventional power plants.

\subsection{Dispatch algorithm to determine the hourly electricity mix}

The country-aggregate electricity demand must be supplied using the available sources which are dispatched in a given merit order. The following steps are completed for every hour $h$, corresponding to a future year $y^{*}$ and assuming the time series combination $j$. They are summarized in Fig. 8.

1. The electricity demand $D_{h}^{y^{*}}$ is estimated by using the value in $h$ of the normalized demand time series $\widehat{D}_{h}^{j}$ included in the combination $j$ and the annual average demand $D_{\text {ave }}^{y^{*}}$ for the year $y^{*}$, which, in turn, depends on the hypothesis made for the evolution of the electricity demand in the transition path under analysis.

$D_{h}^{y^{*}}=D_{a v e}^{y^{*}} \widehat{D}_{h}^{j}$

Likewise, the maximum electricity $E_{h}^{t, y^{*}}$ that can be generated by every technology $t$ is calculated by multiplying the value in $h$ of the capacity factor $C F_{h}^{t, j}$ included in the combination $j$ and the cumulative installed capacity of that technology $C_{h}^{t, y^{*}}$, which, in turn, depends on the transition path under analysis.

$$
E_{h}^{t, y^{*}}=C F_{h}^{t, j} C_{h}^{t, y^{*}}
$$

The variables accounting for the filling levels of hydro reservoirs (conventional $e_{h}^{C O N}$ and mixed $e_{h}^{M I X}$ ) are updated. To do this, the hydro inflow $i n_{h}^{j}$ is split between them (proportionally to their nominal capacities). If the maximum filling level for any of the hydro reservoirs $\left(e^{C O N, \max }, e^{M X X, \max }\right)$ is exceeded, the overflow is spilled without producing any electricity.

$e_{h}^{C O N}=e_{h-1}^{C O N}+i n_{h}^{j} \frac{C^{C O N}}{C^{C O N}+C^{M R}}$

s. t. $\quad e_{h}^{C O N} \leqslant e^{C O N, \max }$

$e_{h}^{M L X}=e_{h-1}^{M L}+i n_{h}^{j} \frac{C^{M L X}}{C^{C O N}+C^{M X}}$

s. t. $e_{h}^{M I X} \leqslant e^{M I X, \max }$

2. Nuclear energy $E_{h}^{\text {nuclear, } y^{*}}$ is used to fill the electricity demand $D_{h}^{y^{*}}$.

3. The remaining electricity demand continues to be filled with coal energy $E_{h}^{c o a l, y^{*}}$.

4. The remaining demand continues to be filled with small hydro $E_{h}^{\text {small-hydro, } y^{*}}$ and cogeneration $E_{h}^{\text {cogen, } y^{*}}$ energy.

5. The remaining demand continues to be filled with CSP energy $E_{h}^{C S P, y^{*}}$.

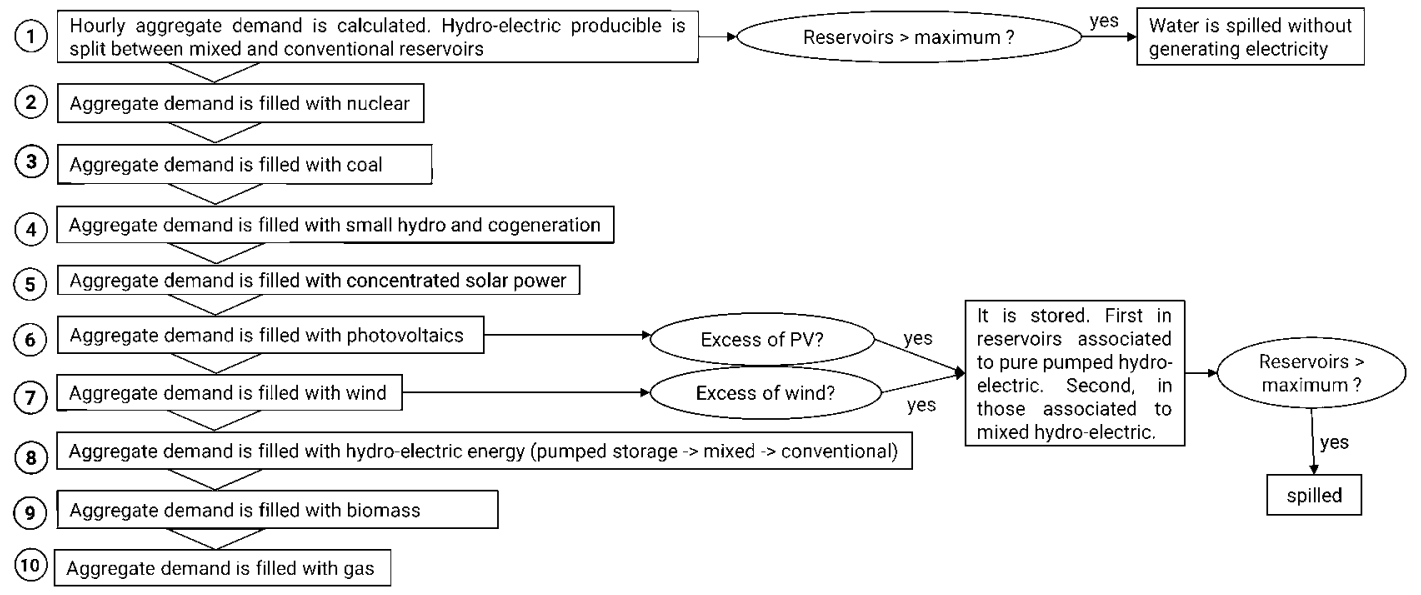

Fig. 8. Scheme of the main steps followed by the dispatch algorithm to determine the hourly electricity mix. 
6. The remaining demand continues to be filled with photovoltaic solar energy $E_{h}^{P V, y^{*}}$.

7. If the potential PV generation is higher than the remaining electricity demand, the excess of energy may be stored. The maximum energy that can be stored is determined by the least of the following values: (a) pump capacity of mixed $C^{M \Gamma X}$, sto and pure-pumped-reservoirs $C^{P H S \text { sto }}$ hydroelectric power plants, and (b) difference between maximum storage capacities of those reservoirs and their current filling levels. If some energy is stored, the filling levels of the reservoirs are updated (Eqs. (19) and (21)). Two caveats need to be mentioned here. In the first place, the criterion to fill the reservoirs prioritizes the pure-pump ones. Hence, no water is stored in mixed reservoirs until pure-pump reservoirs have reached their maximum capacity. If every reservoir is at its maximum allowed level, PV energy is curtailed.

$E_{h}^{P H S, s t o}=\min \left\{\right.$ excess $\left.E_{h}^{P V}, C^{P H S, s t o}, e^{P H S, \max }-e_{h-1}^{P H S}\right\}$

$E_{h}^{M I X, s t o}=\min \left\{\operatorname{excess} E_{h}^{P V}-E_{h}^{P H S, s t o}, C^{M I X, s t o}, e^{M L X, m a x}-e_{h-1}^{M I X}\right\}$

In the second place, when temporary exchanging energy by, first, pumping water and, then, using the water potential energy to spin a turbine, the efficiency of the process is lower than 1 . For peninsular-Spain hydroelectric storage system, an average round-cycle efficiency of $\eta_{s}=70 \%$ has been considered. ${ }^{6}$

8. The remaining demand continues to be filled with wind energy $E_{h}^{w i n d, y^{*}}$. Step number 7 is repeated and excess of wind energy is stored or curtailed.

9. If needed, the remaining demand continues to be filled with hydro energy $E_{h}^{\text {hydro, } y^{*}}$. This step comprises three sub-steps:

Pure-pump reservoirs are the first to be drained. In this way, they will be ready to store energy in the subsequent hours. The maximum energy that can be generated $E_{h}^{P H S, g e n}$ is the least of the following values: (a) generation capacity of pure-pumped-storage hydroelectric installations $C^{P H S, g e n}$, and (b) difference between the filling level of pure pump reservoirs $e_{h}^{P H S}$ and the minimum value allowed for them $e^{P H S, \min }$.

$E_{h}^{P H S, g e n}=\min \left\{C^{P H S, g e n}, e_{h}^{\text {PHS }}-e^{\text {PHS, min }}\right\}$

$e_{h+1}^{P H S}=e_{h}^{P H S}+\eta_{s} E_{h}^{P H S, \text { sto }}-E_{h}^{P H S, g e n}$

s. t. $\quad e^{P H S, \text { min }} \leqslant e_{h+1}^{P H S} \leqslant e^{P H S, \text { max }}$

The second sub-step consists in making use of mixed hydroelectric power plants. The maximum energy that can be produced $E_{h}^{M I X, g e n}$ is the least of the following values: (a) generating capacity of mixed hydroelectric installations, and (b) the difference between the filling level of mixed reservoirs $e_{h}^{M I X}$ and the minimum value allowed for them $e^{M I X, \min }$.

$E_{h}^{M L X, g e n}=\min \left\{C^{M I X, g e n}, e_{h}^{M I X}-e^{M I X, \min }\right\}$

$e_{h+1}^{M I X}=e_{h}^{M I X}+\eta_{s} E_{h}^{M I X, s t o}-E_{h}^{M L X, g e n}$
s. t. $\quad e^{M I X, \min } \leqslant e_{h+1}^{M I X} \leqslant e^{M I X, \max }$

Finally, the energy from conventional hydroelectric power plants that can be produced $E_{h}^{C O N, g e n}$ is estimated as the least of the

\footnotetext{
${ }^{6}$ The efficiency value assumed for the pump-generation hydroelectric cycle $(70 \%)$ was estimated based on historical data for the pumped and generated energy provided by REE. This value coincides with the figure mentioned in related regulation [36] as well as in previous works [21]. Other authors assumed an efficiency of $75 \%$ for the pump-generation cycle [5].
}

following values: (a) generation capacity of conventional hydroelectric installations $C^{C O N}$,gen, and (b) the difference between the filling level of conventional reservoirs $e_{h}^{C O N}$ and the minimum value allowed for them $e^{C O N, \min }$.

$E_{h}^{C O N, g e n}=\min \left\{C^{C O N, g e n}, e_{h}^{C O N}-e^{C O N, \min }\right\}$

$e_{h+1}^{C O N}=e_{h}^{C O N}-E_{h}^{C O N, g e n}$

s. t. $e^{C O N, \text { min }} \leqslant e_{h+1}^{C O N} \leqslant e^{C O N, \max }$

The total hydroelectric energy that can be produced every hour is calculated as

$E_{h}^{\text {hydro }}=E_{h}^{P H S, g e n}+E_{h}^{M I X, g e n}+E_{h}^{C O N, g e n}$

10. The remaining demand continues to be filled with biomass energy $E_{h}^{\text {biomass }, y^{*}}$.

11. The remaining demand continues to be filled with energy from gas combined-cycle power plants $E_{h}^{g a s, y^{*}}$.

If the gas cumulative installed capacity is not enough to supply the remaining demand, an additional electricity generation from hydro is allowed by imposing that the minimum filling level of reservoirs is $e^{C O N, \text { min }}=0.2$ (only for this particular hour). In practice, this implies saving a certain water volume (hence, energy) to deal with hours in which demand is very close to the available generation. The remaining requirements previously stated for hydro generation, such as the limit imposed by cumulative installed generating capacity, are also considered here.

If for any of the hours within the period 2017-2030 and under any of the different 900 time series combinations assumed, the $E_{h}^{\text {gas }}$ is insufficient to cover the remaining demand the transition path is automatically discarded. Finally, once the electricity generation mix has been determined and the reservoirs levels are updated, the algorithm is run again to solve hour $h+1$.

The initial filling levels for the three kinds of hydro reservoirs are assumed to be 0.3 for the first hour of 2017. This hypothesis does not influence the final results as the generation capacity is largely overdimensioned in the initial year and no critical situations are confronted. For the subsequent years, the filling levels of the reservoirs at the first hour in a year are calculated as the median value of the reservoirs filling levels for the last hour of the previous year (calculated for the 900 time series combinations).

$e_{1}^{k, y}=\underset{j}{\operatorname{median}}\left\{e_{8760}^{k, y-1}\right\}$

\subsection{Definition of assessment criteria}

This section includes the definition of the different criteria that are used to assess the feasibility and characteristics of every transition path.

The coverage ratio (defined as the ratio between the installed dispatchable capacity and the peak demand) has been usually employed to assess the security of supply of a power system. While this criterion may be appropriate for power systems based on dispatchable generation, it provides little information for the case of highly-renewable systems. We propose an alternative procedure to evaluate the security of supply of such systems. To that end, firstly, we define the hourly coverage ratio $C R_{h}$, which is estimated, for every hour, as the ratio between the total energy that could potentially be generated and the aggregate electricity demand $D_{h}$. The energy that could be generated is calculated by adding the energy from non-dispatchable sources $E_{n}^{n o n-d i s p}$ and the maximum energy that dispatchable technologies can produce $E_{h}^{d i s p}$. The former is determined by the hourly capacity factors of non-dispatchable technologies while the latter is limited by the cumulative installed 
capacities of dispatchable technologies (and, in the case of hydroelectric, by the filling levels of the different reservoirs). A critical hour is defined as that with a coverage ratio below 1.2. For every transition path, the distribution of hourly coverage ratios throughout the path, as well as the evolution of the total number of critical hours $N_{c h}$ in every year is plotted (see Figs. 12 and 14). Moreover, as previously mentioned, if one hour shows a coverage ratio below one the transition path is considered unfeasible and automatically discarded.

$E_{h}^{\text {nuclear }}+E_{h}^{\text {wind }}+E_{h}^{P V}+E_{h}^{\text {cogen }}+E_{h}^{\text {small-hydro }}+E_{h}^{C S P}=E_{h}^{\text {non-disp }}$

$E_{h}^{\text {coal, } \text { max }}+E_{h}^{\text {hydro,max }}+E_{h}^{\text {biomass, } \text { max }}+E_{h}^{\text {gas,max }}=E_{h}^{\text {disp }}$

$C R_{h}=\frac{E_{h}^{\text {non-disp }}+E_{h}^{\text {disp }}}{D_{h}}$

$N_{c h}=\sum_{h=1}^{8760} h\left(C R_{h}<1.2\right)$

Secondly, the carbon dioxide emissions associated with the electricity generation every year is estimated using the emission factors gathered in Table 4. For most of the technologies, the assumed emission factors (in units of $\mathrm{grCO}_{2} / \mathrm{kWh}$ ) correspond to Life Cycle Assessments, i.e., they include emissions throughout the fabrication, transportation, installation, and decommissioning of the power plant [37].

Thirdly, the percentage of the electricity demand covered by RES every hour is calculated. Fourthly, the aggregate wind and PV energy that must be curtailed when it cannot be stored since hydro reservoirs are at their maximum levels is also reported. For the sake of clarity, the aggregate curtailed wind and PV energy is expressed as a percentage of the total energy that could have been generated by those sources (assuming unlimited storage). Finally, the analysis of biomass and gas generation is also important in as much as they will mainly operate as backup technologies, meaning that their operating hours may be significantly reduced from todays values. Currently, the installed capacity for combined-cycle gas power plants in Spain is $24.9 \mathrm{GW}$. This capacity is known to be highly overdimensioned since the average annual capacity factor for this technology in the period 2010-2015 has been $11.1 \%$. The maximum hourly energy generated by gas power plants in every year is investigated in every transition path. Furthermore, the evolution of the annual capacity factors for gas and biomass power plants throughout the transition paths are also reported.

\subsection{Cross-validation of the model}

In order to validate the methodology as well as the dispatching algorithm proposed in this work, we carry out an exercise of cross-validation. The time series combinations described in Section 2.3 are employed to simulate the year 2016 (whose data were not used to produce any of the time series combinations) and the results are compared to

\section{Table 4}

$\mathrm{CO}_{2}$ emissions associated with electricity generated by different technologies. For coal, biomass, cogeneration, and gas power plants the figures have been derived from historical data [31]. For the rest of technologies, the figures were obtained through Life Cycle Assessment $[37,53]$.

\begin{tabular}{lc}
\hline & $\mathrm{grCO}_{2} / \mathrm{kWh}$ \\
\hline Coal & 950 \\
Gas (combined cycle) & 370 \\
Biomass & 170 \\
Cogeneration & 370 \\
Nuclear & 16 \\
Small-hydro/Hydroelectric & 4 \\
Wind & 12 \\
Photovoltaics, PV & 20 \\
Concentrated Solar Power, CSP & 22 \\
\hline
\end{tabular}

\section{6}
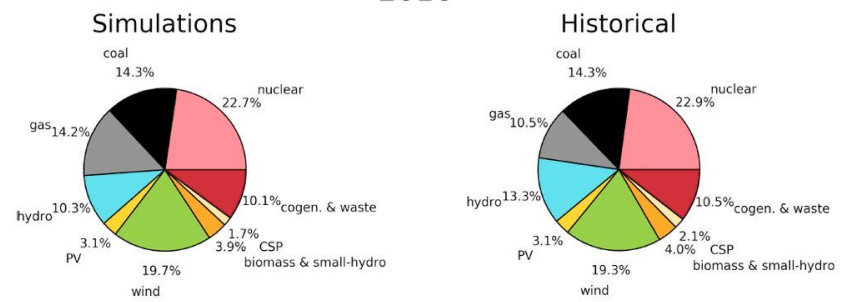

Fig. 9. Contributions of the different technologies to the annual electricity mix in 2016. (left) Values predicted from simulations including 900 time series combinations. (right) Historical data provided by REE. For 2016, REE does not provide the energy produced by small hydroelectric power plants but only the aggregate value together with large hydroelectric power plants. It has been assumed that the share of small-hydro annual electricity generation is the same as in 2014 (last year when disaggregated information is provided).

historical values. We note here that the simulation does not aim to reproduce current operation of the electricity system but rather a possible future operation. However, since the merit order included in the dispatching algorithm roughly resembles what happens in reality (e.g., electricity from coal and nuclear is produced when the capacity is available due to its low market bids), annual integrated values are expected to agree to some extent.

Fig. 9 depicts the simulated and historical electricity mix for 2016. Percentage figures for most of the technologies are very similar. For hydroelectricity, the historical value is significantly higher than the simulated one. This can be explained by the fact that the historical total hydro inflow for the year 2016 was 15\% higher than the average for the previous 20 years (and also 15\% higher than the 5 hydroelectric inflow time series included in the 900 simulated combinations, see Fig. 5). Consequently, the share of electricity covered by gas power plants resulted to be higher in simulations than in reality.

The evolution of the filling levels of reservoirs associated with conventional hydroelectric power plants in the simulations can be analyzed by observing Fig. 10. The dispatch algorithm imposes that, while the filling levels of the mixed and conventional reservoirs are higher than $30 \%$, hydroelectric energy is prioritized over biomass and gas with the objective of minimizing $\mathrm{CO}_{2}$ emissions. In order to represent the time evolution of water reservoirs throughout the year, the minimum filling level allowed follows a concave down shape in spring and summer. In winter and autumn, the minimum allowed value is returned to $30 \%$. In 2016, the historical time evolution of the reservoirs associated with conventional hydroelectric power plants was at every moment higher than the median of the 900 simulated combinations. The reasons for that are twofold. First, as previously mentioned, the actual annual hydro inflow was significantly higher than the average value for the inflow time series included within the 900 simulated combinations. Second, the algorithm maximizes the use of hydroelectric energy which does not represent the actual use of hydroelectric power plants but rather an ideal use when the minimum $\mathrm{CO}_{2}$ emissions condition is sought.

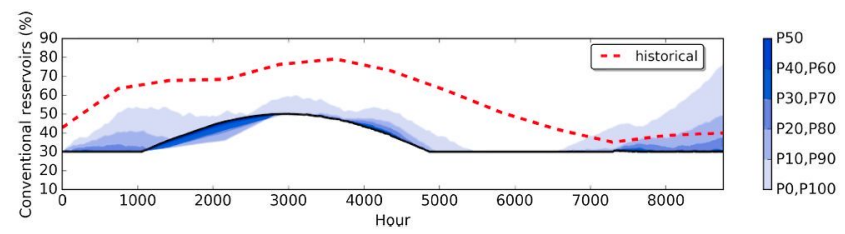

Fig. 10. Filling level of reservoirs associated with conventional hydroelectric power plants in 2016. The simulations based on 900 time series combinations (percentiles shown by different blue shades) can be compared with the actual historical evolution (red line). (For interpretation of the references to color in this figure legend, the reader is referred to the web version of this article.) 


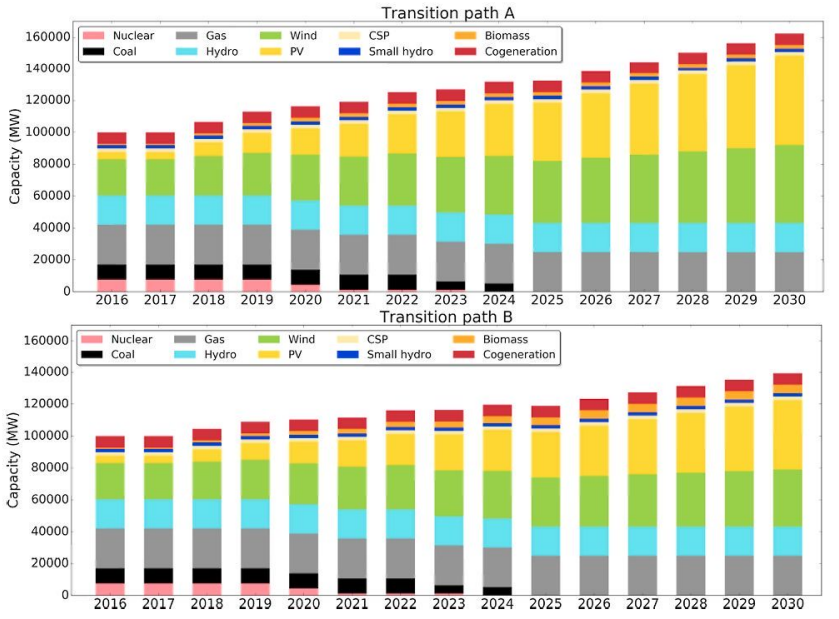

Fig. 11. Cumulative installed capacities for different technologies (on the 31st of December) of every year in transition path A and B.

\section{Transition paths under analysis}

This section includes the description of two alternative paths investigated to significantly reduce the $\mathrm{CO}_{2}$ emissions from the electricity generation in peninsular Spain by 2030 . On the one hand, transition path $A$ is characterized by low cumulative installed capacity of biomass power plants. It relies mostly on realistic but ambitious deployments of wind and PV capacities. On the other hand, transition path B increases the cumulative installed capacity of dispatchable RES (biomass power plants) and includes more modest values for the cumulative installed capacities of non-dispatchable RES (wind and PV).

\subsection{Transition path $A$}

In the transition path $\mathrm{A}$, it is assumed that thanks to efficiency and saving policies, the electricity demand increment is contained so it increases only by $0.5 \% /$ year. In the case that efficiency increment and savings caused demand to stagnate, the excess of electricity could be used to electrify other sectors such as transportation or domestic heating and cooling, enabling a straightforward strategy for their decarbonization. The hypotheses on the installed and decommissioned capacities for every technology are summarized in Fig. 11. Every year, $4 \mathrm{GW}$ of PV are installed until a cumulative capacity of $56 \mathrm{GW}$ is reached. For wind power plants, an annual installation rate of $2 \mathrm{GW}$ is maintained until the cumulative capacity equals $48.8 \mathrm{GW}$. For the three initial years, $0.5 \mathrm{GW} /$ year of biomass are installed until the total cumulative capacity reaches $2.2 \mathrm{GW}$. For the sake of simplicity, when we indicate that a certain capacity is installed in a year, we are assuming that the total cumulative capacity of that technology increases by that amount, that is, the fraction of the previously installed capacity that reaches the end of its lifetime in every year, or the reduction in power due to, for instance, PV plants degradation caused by aging, is assumed to be replaced. Hydroelectric power plants, either small or large scale, and their associated reservoirs are assumed to remain constant at the values of 2016 (see Table 3). For nuclear power plants, it is assumed that their current operation licenses are not renewed. ${ }^{7}$ Hence, the phase-out will take place as their licenses expire, ${ }^{8}$ the last one in 2024

\footnotetext{
${ }^{7}$ Nuclear licenses in Spain are valid for 10 -year periods. They are granted by the Government and require the agreement of the national Nuclear Security Council. All the nuclear plants currently in operation in Spain will reach their 40-years operation life in less than 10 years, meaning that, if new 10 -years licenses are granted, they would require operation life extensions.

${ }^{8}$ An alternative transition path A2 including a delayed nuclear shutdown is analyzed in the Supplementary Materials.
}

Table 5

Shutdown schedule assumed for nuclear power plants in transition paths $\mathrm{A}$ and B. The fourth column represents the shutdown schedule for transition path A2 where a delayed nuclear shutdown is considered. The details for transition path A2 can be seen in Supplementary Materials.

\begin{tabular}{cccc}
\hline $\begin{array}{c}\text { Nuclear power } \\
\text { plant }\end{array}$ & Capacity (MW) & $\begin{array}{c}\text { Shutdown (paths A } \\
\text { and B) }\end{array}$ & $\begin{array}{c}\text { Shutdown (path } \\
\text { A2) }\end{array}$ \\
\hline Almaraz I & 1049.4 & 2020 & 2023 \\
Almaraz II & 1044.5 & 2020 & 2024 \\
Vandellós II & 1087.1 & 2020 & 2028 \\
Ascó I & 1032.5 & 2021 & 2024 \\
Cofrentes & 1092.0 & 2021 & 2025 \\
Ascó II & 1027.2 & 2021 & 2026 \\
Trillo & 1066.0 & 2024 & 2028 \\
\hline
\end{tabular}

Table 6

Shutdown schedule assumed for coal power plants in transition paths A and B.

\begin{tabular}{ccc}
\hline Coal power plants & Capacity (MW) & Shutdown \\
\hline $\begin{array}{c}\text { Power plants that initially opted for limited } \\
\text { lifetime derogation } \\
\text { Remaining power plants }\end{array}$ & 4300 & 2023 \\
\hline
\end{tabular}

(see Table 5). A fraction of the currently installed coal power plants are assumed to cease their activities in 2023 while the rest are shut down in 2025 (see Table 6). We elaborate below on these hypotheses.

Regarding the demand evolution, the $0.5 \%$ annual increment assumed here may seem low since other authors include rates up to $2 \%$ / year. However, it should be remarked that a large demand increment is not imperative to enhance social welfare. For instance, the EUCO30 scenarios analyzed by the European Commission (in which the EU commitments in terms of emissions, renewables, and efficiency are met through the most cost-effective manner) include an evolution of the electricity demand in Spain of $-0.5 \%$ /year within 2010-2020 and $-0.3 \%$ /year within 2020-2030. For the whole EU, the EUCO30 scenario includes an electricity demand increment of $0.1 \% /$ year throughout both decades [38].

We believe that the annual installation rates for wind and PV are certainly viable and the cumulative capacities lie below the estimated potentials in both cases. Since the construction times for wind and PV power plants are estimated between 6 months and 2 years, considering the current costs of both technologies, and once the necessary regulatory stability is ensured, the assumed installation rates could be achieved. To justify this statement, the German experience can be illustrative. In the last decade, the average PV installation rate in Germany has been higher than $4 \mathrm{GW} /$ year. In fact, in 2010, 2011, and 2012 the rates were above $7 \mathrm{GW} /$ year. Consequently, at the end of 2016 , the cumulative PV capacity in that country reached $41.2 \mathrm{GW}$ [39].

For those technologies whose impacts on the local environment could be more significant, their developments have been severely limited in transition path A. Biomass maximum cumulative installed capacity is $2.2 \mathrm{GW}$ while no additional capacity, apart from that currently installed in 2016, is assumed for small or large hydroelectric power plants.

Since January, 1st 2016, European coal power plants are forced to meet the emissions limit values established by Directive $2010 / 75 / \mathrm{EU}$ on industrial emissions. Initially, some of the Spanish coal power plants, accounting in total for $4300 \mathrm{MW}$, opted for the limited lifetime derogation $[40,41]$. These power plants are exempt from respecting the emission limit values but can operate only during a reduced number of hours and they must cease their activities before December, 31st 2023. In both transition paths, it has been assumed that the $4300 \mathrm{MW}$ coal capacity that initially opted for limited lifetime derogation is shut down on that date and the remaining coal capacity is closed by the end of 


\subsection{Transition path $B$}

Transition path B shares most of the hypotheses of transition path A: the progressive phase-out of nuclear and coal is identical, the hydroelectric capacities are also assumed to remain constant, and the time evolution of demand is based on an increment of $0.5 \% /$ year (representing the combined effect of efficiency and saving policies together with possible electrification of other sectors). The only difference for transition path $\mathrm{B}$ consists in a reduced installation of non-dispatchable RES capacities (wind and PV) counterbalanced by a higher cumulative installed capacity for dispatchable RES. Biomass is envisaged as the main source of dispatchable renewable capacity. Geothermal could also complement it although its potential in peninsular Spain is significantly lower. The detailed figures are as follow. PV is installed at $3 \mathrm{GW} /$ year until the cumulative capacity reaches $43 \mathrm{GW}$; wind is installed at $1 \mathrm{GW} /$ year until the cumulative capacity reaches $35.8 \mathrm{GW}$; and biomass is installed at $0.5 \mathrm{GW} /$ year for the nine initial years up to $5.2 \mathrm{GW}$ of cumulative capacity.

\section{Results and discussion}

\subsection{Transition path $A$}

Fig. 12 depicts the time evolution of the main criteria that are used to evaluate transition path A. The distribution of probability of hourly Coverage Ratio (ratio of energy that can be potentially produced to demand as defined in Eq. (28)), is shown in Fig. 12a. This information is processed to obtain Fig. 12b, where it can be observed how the number of critical hours (those whose coverage ratio is lower than 1.2 ) is below 700 for every year under analysis. The $\mathrm{CO}_{2}$ emissions caused by electricity generation is cut down from 60 million tons at present to less than 26 million tons in 2030 (Fig. 12c). Consequently, the carbon intensity decreases from $239 \mathrm{grCO}_{2} / \mathrm{kWh}$ at the beginning to $94 \mathrm{grCO}_{2} /$ $\mathrm{kWh}$ at the end of the path. $\mathrm{CO}_{2}$ emissions in 2016 accounted for $242 \mathrm{grCO}_{2} / \mathrm{kWh}$ [31]. The renewable share of the total generation doubles from $38 \%$ in 2017 to $79 \%$ in 2030 (Fig. 12d). But also, as the renewable generation increases, the need for curtailment becomes more significant reaching $13 \%$ of the total RES generation in 2030 (Fig. 12e).

A detailed analysis of the performance of pure-pumped-reservoir hydroelectric power plants reveals that for most of the hours when PV and wind are curtailed, pumping power was at its maximum capacity preventing any additional energy storage. Several projects to increase pumping capacity are currently under analysis in peninsular Spain [21] that could reduce the renewable curtailment in transition path A.

The distribution of the maximum instantaneous gas power used every year is shown in Fig. 12f. In 2023, when the nuclear and coal phase-out is close to ending, this distribution concentrates in the cumulative installed gas capacity that has been kept constant throughout the transition (at 2016 value). Hence, under the assumed hypotheses, all the gas power plants that are currently installed will be necessary to back up RES generation throughout transition path A. Furthermore, as depicted in Fig. 12g, they will be operated with annual capacity factors around $20 \%$. Finally, Fig. $12 \mathrm{~h}$ shows the evolution of annual capacity factor for biomass power plants. The necessary amount of biomass fuel can be estimated from this figure. However, the analysis on how to produce this biomass in a sustainable manner is out of the scope of this work.

Fig. 13 depicts the electricity mix in 2030 if transition path $\mathrm{A}$ is followed. The shares of $\mathrm{CO}_{2}$ emitted by different technologies are also shown. Half of the emissions are caused by cogeneration and RES. The use of fuels with lower emissions in the former will reduce the total amount of $\mathrm{CO}_{2}$ emissions estimated for 2030. In addition, the emission factors assumed for RES (which are based on their Life Cycle Assessment, see Table 4) also has a direct impact in total $\mathrm{CO}_{2}$ emissions. mentioning that the configuration of the cumulative installed capacities in 2030 is similar, to some extent, to that proposed by Breyer et al. [26]. These authors determine, for several regions across the world, the leastcost capacities mix that allows $100 \%$ renewable supply of primary energy demand in 2030 . For the Iberian peninsula, i.e., they analyze Spain and Portugal as a whole, the optimum configuration comprises, among others, $41.9 \mathrm{GW}$ of wind capacity and $120.6 \mathrm{GW}$ of PV capacity, which, in turn, includes $59.4 \mathrm{GW}$ in rooftop installations together with 61 and $55.1 \mathrm{GW}$ in utility-scale power plants, static or tracking respectively. The work by Breyer and coauthors agrees in highlighting that wind and PV are the most cost-effective pillars where the transition towards a low $\mathrm{CO}_{2}$ emissions power system in Spain must be supported. The optimum capacity of PV proposed by them is significantly larger than the figures assumed here since their model aims to supply primary energy demand while we restrict the model to electricity demand.

PV and wind are also the main sources of energy in the optimum system determined by Jacobson et al. [19] for the year 2050. These authors propose the electrification of other sectors (heating/cooling, industry, and transportation) as the best strategy to achieve a fully renewable supply for final energy demand. In the optimum scenario that Jacobson and coauthors determine for Spain, the final energy needed in 2050 is generated by $35.7 \%$ wind $(25.7 \%$ onshore and $10 \%$ offshore), $43.3 \% \mathrm{PV}$ ( $20 \%$ in rooftops and $20.3 \%$ ground installations), $11 \%$ CSP, and $8.6 \%$ hydroelectric power plants.

\subsection{Transition path $B$}

The global analysis of transition path B can be performed observing Fig. 14. The evolution of the number of critical hours is similar to that of transition path A. In both cases, critical hours maximize in the years following the shutdown of nuclear and coal power plants. The evolution of renewable share in total electricity is similar too, but transition path $\mathrm{B}$ reaches a slightly lower figure in 2030 (76\%). Curtailed renewable energy is noticeably different between both transition paths. While this figure reaches $26.9 \mathrm{TWh}$ in 2030 for path A, it gets reduced to $7.5 \mathrm{TWh}$ in path $\mathrm{B}$. This result is intuitive as the latter includes a higher amount of dispatchable RES capacity. The abatement of $\mathrm{CO}_{2}$ emissions for path $\mathrm{B}$ is less pronounced than for path $\mathrm{A}$. The median $\mathrm{CO}_{2}$ emissions in 2030 for transition path $B$ is 36 million tonnes. For this assessment criteria, a wide dispersion is found during the initial years for both paths. The reason is that as long as coal power plants remain in operation, their different performance in the 900 time series combination has an enormous impact on the total $\mathrm{CO}_{2}$ emissions. Under the hypotheses of transition path $\mathrm{B}$, the gas capacity already installed in 2016 becomes also necessary at some point in the path. Gas and biomass annual capacity factors remain below $30 \%$ and $70 \%$ respectively throughout the transition path.

Fig. 15 depicts the pie charts for electricity generation and $\mathrm{CO}_{2}$ emissions in 2030 if transition path B is followed. As expected, the share of electricity with biomass origin, and consequently the associated $\mathrm{CO}_{2}$ emissions are higher than in transition path $\mathrm{A}$.

One fundamental question arises from this transition path: what would be the environmental impact of the biomass electricity? or in other words, can we produce the biomass required to operate the installed capacity in a sustainable manner? The detailed analysis of these questions is out of the scope of this work so we limit ourselves to some preliminary evaluation. Taking into consideration that the annual capacity factor of biomass power plants is expected to be lower than $70 \%$ for every year within the transition path B (see Fig. 14h) and that cumulative capacity maximizes at $5.2 \mathrm{GW}$, the annual electricity generated burning biomass will be roughly $32 \mathrm{TWh}$. This figure is far below the maximum biomass potential estimated for peninsular Spain by other authors: 65.2 TWh in [21], 71.6 TWh in [42] and 141.5 TWh in [24].

Before concluding the analysis of transition path $\mathrm{B}$, it is worth 

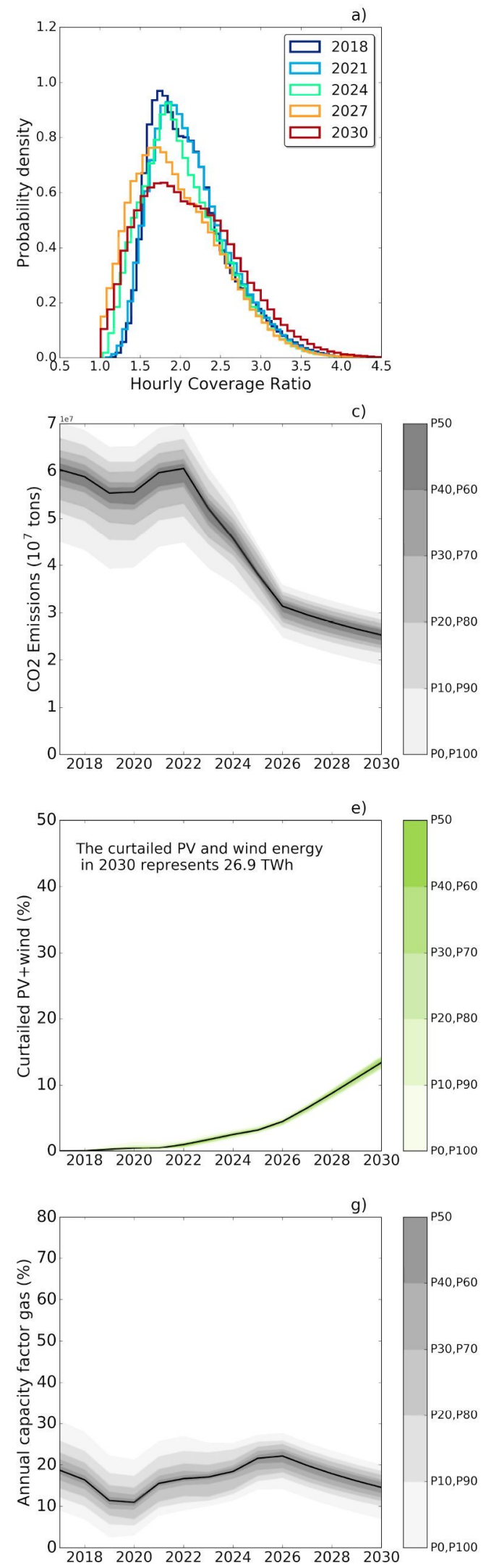
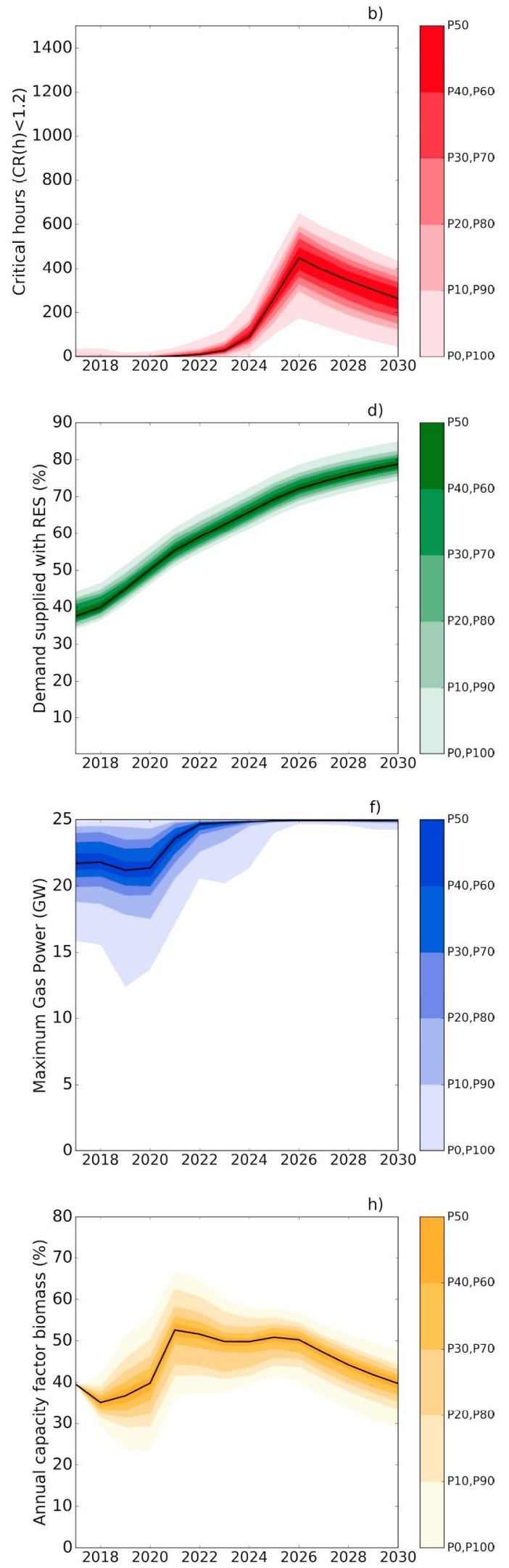

Fig. 12. Time evolution of the main assessment criteria evaluated for transition path A. (a) Probability distribution of Coverage Ratio, $C R_{h}(r a t i o$ of available generation to demand) for every hour in the period 2017-2030. For the following subfigures, the black line indicates the median, or percentile 50, and the color bars show the shades associated with every percentile range. (b) Number of critical hours $N_{c h}$ in every year in which $C R_{h}$ is lower than 1.2 . (c) $\mathrm{CO}_{2}$ emissions associated with electricity generation. (d) Share of RES in electricity generation. (e) Curtailed RES (relative to RES that could be potentially generated). (f) Maximum instantaneous power delivered by gas power plants in every year. $(\mathrm{g})$ Annual capacity factor of gas power plants. (h) Annual capacity factor of biomass power plants. 

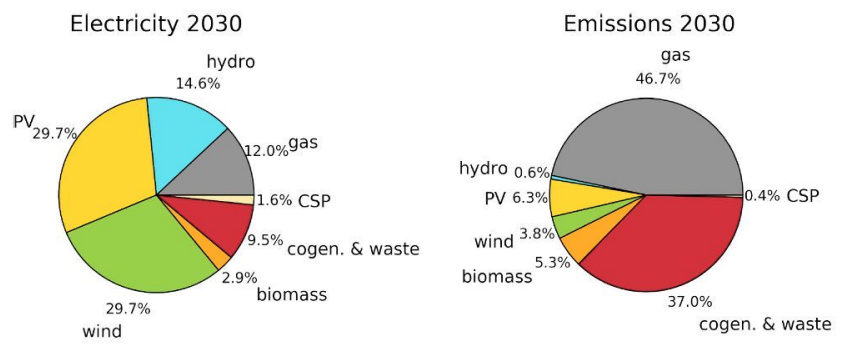

Fig. 13. (left) Electricity mix in 2030 for the transition paths A. (right) Technologies responsible for the main emissions of $\mathrm{CO}_{2}$ in 2030 in transition path A.

mentioning that the assumption regarding dispatchable renewable cumulative installed capacity, i.e., biomass, is similar to those in [21] where the two alternative scenarios considered include $8.3 \mathrm{GW}$ and $11.8 \mathrm{GW}$ of biomass capacity.

\subsection{Impact of a delayed nuclear phase-out (Transition path A.2)}

To investigate the impact of delaying the nuclear phase-out, a slightly modified transition path is simulated. All the assumptions, except those around the nuclear phase-out, are the same as in transition path A. For the nuclear phase-out, it is assumed that every nuclear power plant gets its operating license extended until it reaches a total operating life of 40 years.

There are three significant impacts derived from this decision. In the first place, the $\mathrm{CO}_{2}$ emissions are reduced (as described in the next subsection). In the second place, a noticeable increment of the curtailed renewable energy is predicted, which is particularly noticeable for the years where the nuclear shutdown is delayed (2023-2025). In the third place, the available gas capacity is heavily underused before 2026 . The median of the maximum instantaneous power of gas used every year decreases, particularly around 2023. However, once the nuclear phaseout is completed, the $25 \mathrm{GW}$ of currently installed gas capacity are again needed and median annual capacity factor increases to $15 \%$. The figure including the evolution of the assessment criteria for transition path A2 is provided in the Supplementary Materials.

\section{4. $\mathrm{CO}_{2}$ emissions for different transition paths}

Fig. 16 depicts the $\mathrm{CO}_{2}$ emissions including historical values as well as those predicted through the simulations (percentile 50 is shown for transition paths A, B, and A2). Both transition paths, A and B, show a similar time evolution but, in 2030 , emissions in path B are higher due to the higher share of biomass. The difference between emissions in 2030 is determined by the $\mathrm{CO}_{2}$ emission factor assumed for biomass (Table 4). If we compare now emissions for paths $\mathrm{A}$ and its alternative version A2 (where operation life for nuclear power plants is extended), $\mathrm{CO}_{2}$ emissions in 2030 are the same. This result was expected since the capacities mix for both paths in the final year is exactly the same. However, for some years in the investigated period, path A2 shows lower emissions. The emissions difference integrated through the entire period accounts for 67 million tons $\mathrm{CO}_{2}$. Two additional remarks are needed to contextualize this result. First, the dispatch order imposed by the algorithm (Section 2.5) implies that, if nuclear is not present, the first technology to be used is coal (we should remind here that the reduction in coal-based electricity generation is imposed by the phaseout schedule included in every transition path). If a different dispatch order were applied, the accumulated emission difference between path A and A2 would be reduced. Second, the extension of nuclear power plants operation life included in path A2 requires that, during several years, gas power plants do no generate almost any electricity although they are again needed at the end of the path.

\subsection{Impacts of droughts caused by climate change}

One of the most significant impacts of climate change in peninsular Spain is the occurrence of more frequent or severe drought conditions. Hence, the hydroelectric output is one of the most sensitive parameters when modeling future energy scenarios. In fact, as a result of climate change, the average hydroelectric inflow in peninsular Spain is predicted to decrease by $8 \%$ in the period 2011-2040 [43]. Transition path $\mathrm{A}, \mathrm{B}$, and $\mathrm{A} 2$ were rerun assuming a reduction of $8 \%$ in the hydro inflow time series corresponding to each of the 900 combinations. Results showed that the transition paths are also valid under the more severe conditions, i.e., demand can be supplied by available energy at every hour.

\subsection{Impact of higher electricity demand increment}

Transition paths A, B, and A2 assumed a constant electricity demand increment of $0.5 \% /$ year. We do not want to impose the condition that demand from the electricity sector will unavoidably increase but rather include some margin for the electrification of other sectors as a straightforward strategy to decarbonize them. In 2030, transportation (through electric vehicles), domestic heat/cooling demand (through heat pumps), and, to a lesser extent, industrial demand could be electrified. For instance, it can be assumed that, as a result of efficiency and saving policies, the annual electricity demand stagnates at 2016-value (250 TWh). Then, the $0.5 \%$ year increment rate, which translates into an accumulated $6.7 \%$ increment in 2030 , represents 16.7 TWh of excess electricity that can be used in other sectors. This is roughly equivalent to the annual consumption of 5.5 millions of electric vehicles, which represent $24 \%$ of the total current individual vehicles fleet in Spain. If the additional electricity is used to supply residential heat demand, assuming a Coefficient of Performance (COP) of 3.65 for heat pumps, $75 \%$ of the demand of this sector in 2015 could be supplied. The electrification of the transportation and heating sectors implies nonnegligible variation on the hourly demand curve [44] but this analysis is out of the scope of the present work.

Finally, it is also worth investigating the scenarios where the rate of increase of electricity demand is higher than $0.5 \%$ /year, either because efficiency policies do not work or because other sectors are electrified at a higher rate. If $1 \%$ year rate of for demand increment is assumed, transition path $\mathrm{B}$ fulfills the condition of supplying demand at every hour for the whole period and under any of the 900 time series combination simulated. For transition path $\mathrm{A}$, this condition is also fulfilled when the rate of increase is $0.7 \%$ /year. If this rate is $1 \%$ /year, there are some hours (in only a few of the time series combinations) in which available generation is lower than demand. This can be addressed by importing electricity from adjacent countries (remember that our model considers peninsular Spain as electrically isolated), applying demandside control strategies or interrupting the supply of large electricity consumers. Moreover, when we carefully analyzed transition path A with $1 \%$ /year demand increment, we realized that, in hours where demand is higher than generation, the hydroelectric conventional power plants are not operating at their maximum level because the corresponding reservoirs are close to the minimum allowed filling level. Hence, we investigate an alternative strategy consisting in increasing the minimum filling level for hydro reservoirs in non-critical hours to $35 \%$ (see Table 3). In this way, the stored water that can only be used in critical hours (this can be calculated as $(0.35-0.20)$ multiplied by the conventional hydroelectric reservoirs storage capacity) is significantly increased, ensuring security of supply for every hour within the transition path. The drawback of this strategy could be the possible increment of spilled water since now the probability of the reservoirs to surpass the maximum filling level is higher. When we repeat the simulations for transition path A assuming 0.35 as minimum filling lever for hydro reservoirs in non-critical hours we find this effect to be negligible, while the supply criterion is matched for every hour in the 

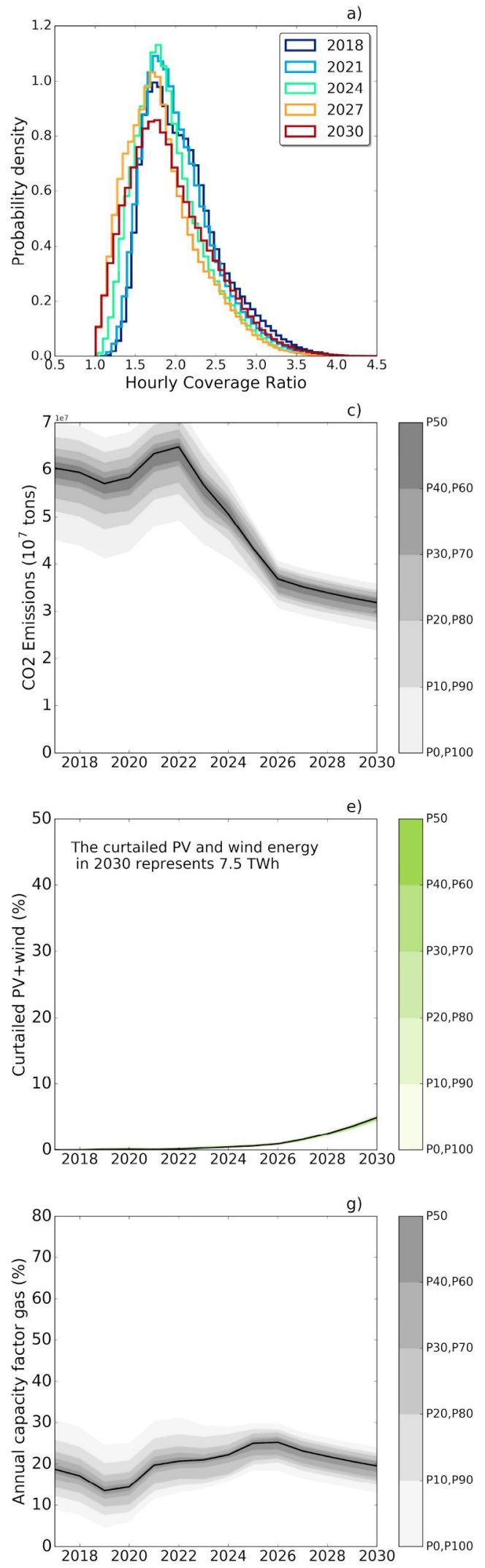
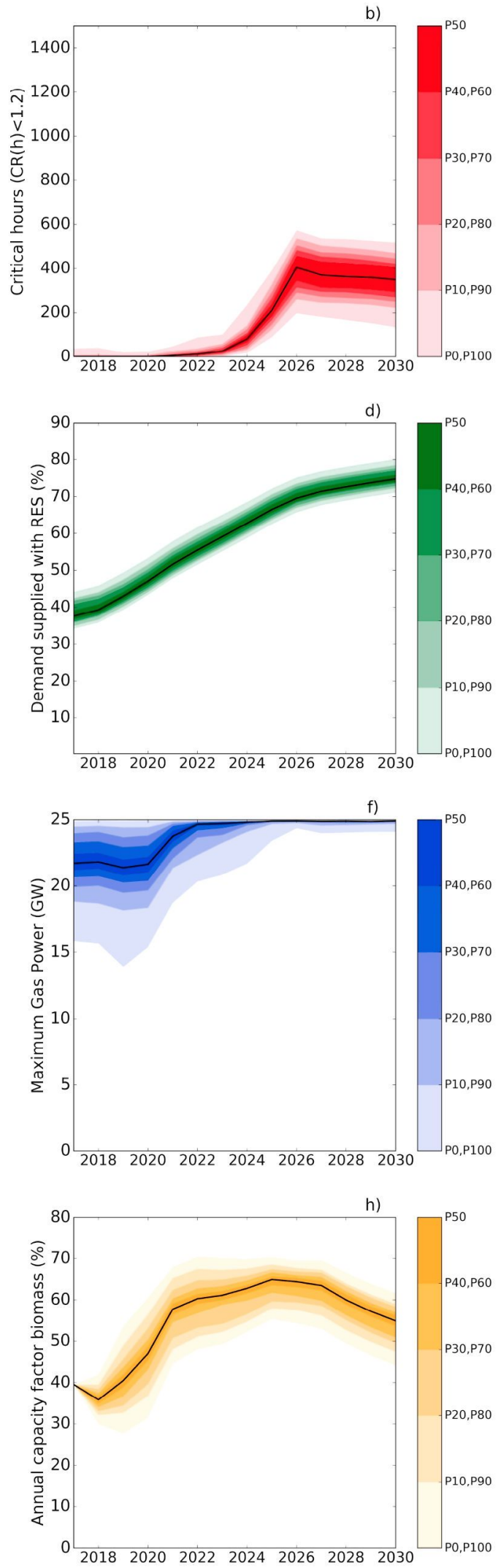

Fig. 14. Time evolution of the main assessment criteria evaluated for transition path B. (a) Probability distribution of Coverage Ratio, $C R_{h}$ (ratio of available generation to demand) for every hour in the period 2017-2030. For the following subfigures, the black line indicates the median, or percentile 50, and the color bars show the shades associated with every percentile range. (b) Number of critical hours $N_{c h}$ in every year in which $C R_{h}$ is lower than 1.2 . (c) $\mathrm{CO}_{2}$ emissions associated with electricity generation. (d) Share of RES in electricity generation. (e) Curtailed RES (relative to RES that could be potentially generated). (f) Maximum instantaneous power delivered by gas power plants in every year. (g) Annual capacity factor of gas power plants. (h) Annual capacity factor of biomass power plants. 

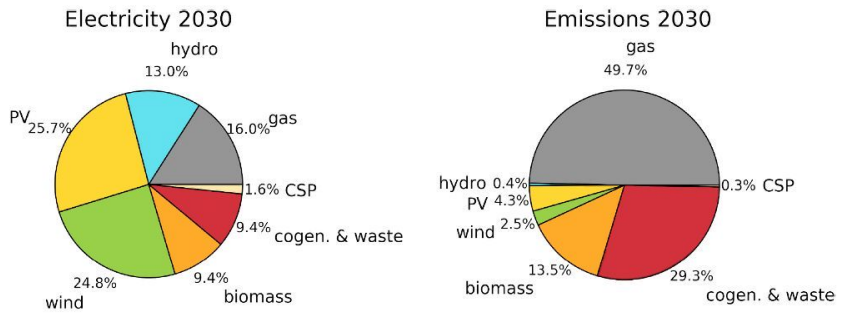

Fig. 15. (left) Electricity mix in 2030 for the transition paths B. (right) Technologies responsible for the main emissions of $\mathrm{CO}_{2}$ in 2030 in transition path B.

transition.

\section{Critical appraisal}

The present work has some significant limitations that are worth mentioning. In the first place, the implemented dispatch algorithm solves the electricity mix to supply aggregate electricity demand in peninsular Spain. In essence, the "copper plate" approach that is followed neglects any possible limitation due to congestion in the transmission and distribution networks.

In the second place, it has not been analyzed how the power system ability to recover from perturbations evolves since the system inertia is reduced as the shares of wind and PV increase throughout the transition paths. This is an active research area nowadays, for instance, new generation PV inverters include both fast-response to perturbations and inertia emulation capabilities. The installation of synchronous compensators in the transmission grid is also a common strategy to deal with situations with high renewable generation shares [45,46]. As a preliminary analysis, Fig. 17 shows the distribution probability of synchronous generation power for every hour in transition path $\mathrm{A}$. The lower limit of $5 \mathrm{GW}$ of synchronous generation for the initial years can be considered an acceptable figure for addressing perturbation episodes. At the end of the period, in 2030, a strong decrease of synchronous generation is observed and should have been addressed through the implementation of the aforementioned strategies.

In the third place, the feasibility of peninsular Spanish power system has been evaluated considering it an isolated system, i.e., ignoring the interconnection capacities to adjacent countries and Balearic Island. Although including these interconnections, mainly with France, could facilitate the system operation, our work also shows that increasing the interconnection capacity is not indispensable to achieve high renewable penetration in peninsular Spain. Demand-side control is also a useful

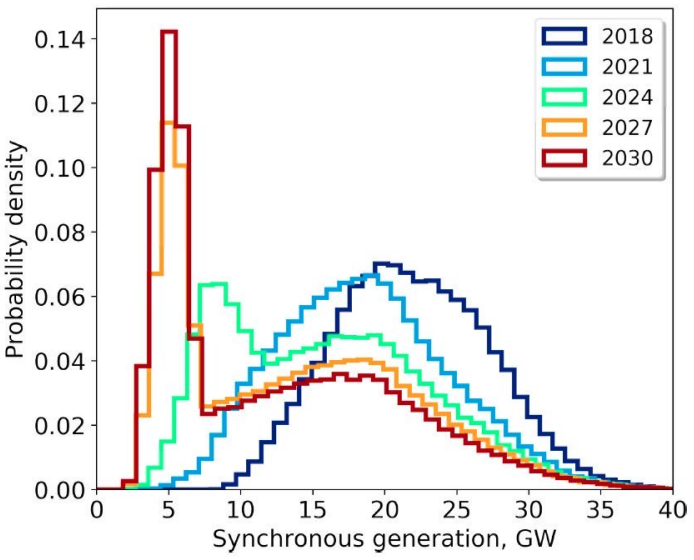

Fig. 17. Distribution probability of synchronous generation power for every hour. Several years included in transition path A are shown. Technologies included in synchronous generation are nuclear, coal, gas, biomass, CSP, cogeneration, hydro, and small-hydro.

tool to cope with critical situations that has not been included in this work. The interconnection of the power system with other sectors such as transportation or heating and cooling is not included either.

Finally, the cost estimation for the investigated transition paths is lacking. Nevertheless, there are several previous works, referenced throughout this text, that showed how power systems with high-renewable penetration can achieve a total cost similar to current figures, even when taking into consideration the additional infrastructures or auxiliary services required to make the system operation safe. In particular, the cost of the optimum electricity mix determined by Galbete et al. [47] for peninsular Spain is lower than todays. The job creation associated with every transition path is not calculated either. However, there is significant evidence on the fact that substituting fossil fuelbased generation by RES-generation implies net job creation [48].

\section{Conclusions}

A model to simulate the hourly electricity supply in peninsular Spain has been implemented where a simple dispatch algorithm that prioritizes renewables is used to configure the hourly electricity mix. A proposed methodology to select time series from available historical data based on their correlation is used to obtain the 900 time series combinations employed in the simulations.

The progressive and simultaneous phase-out of coal and nuclear power plants in Spain within the next decade has been proven to be

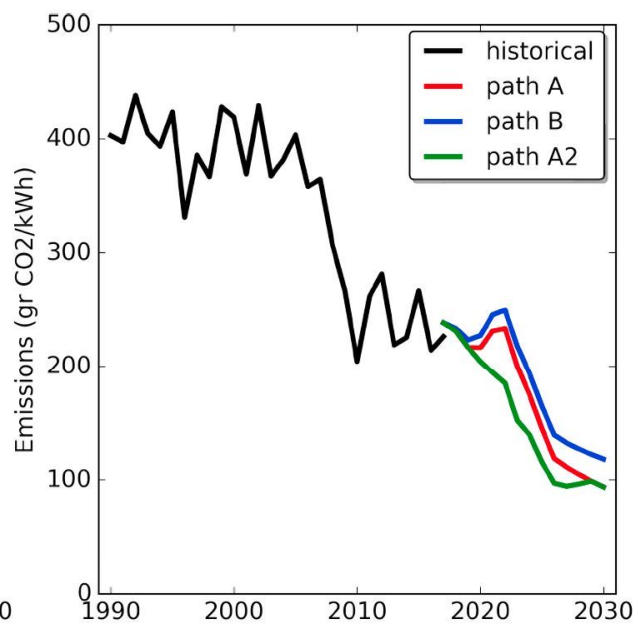

Fig. 16. Historical and median values predicted for transition paths $\mathrm{A}, \mathrm{B}$ and $\mathrm{A} 2$ : (a) $\mathrm{CO}_{2}$ emissions caused by electricity generation. (b) Electricity generation carbon intensity (gr $\left.\mathrm{CO}_{2} / \mathrm{kWh}\right)$. 
compatible with a transition towards a highly-renewable electricity system. Two alternative transition paths were investigated. Path A assumes higher rates and cumulative installed capacities for non-dispatchable renewables (wind and PV) while keeping the cumulative capacity of dispatchable renewables (biomass) low. Path B restrains the wind and PV installed capacities and raises the cumulative capacity for biomass power plants. In both transition paths, security of supply is ensured for every hour within the period 2017-2030 and for any of the 900 different time series combinations. The evolution of $\mathrm{CO}_{2}$ emissions and renewable generation share is similar in both cases. $\mathrm{CO}_{2}$ emissions decline from 60 million tons in 2017 to 26 million tons (path A) and 36 million tones (path B) in 2030. Renewable generation share boosts from $38 \%$ to $79 \%$ (path A) and $76 \%$ (path B) in the same period. As expected, the curtailed renewable energy is lower for the transition path with higher dispatchable renewable capacity. For the investigated period (2017-2030), the currently installed capacity of gas power plants would operate with an annual capacity factor of approximately $20 \%$ but a capacity factor of $100 \%$ would be necessary at some hours to secure supply. Additional analyses proved the robustness of the transition paths under a higher increase in demand (up to $1 \%$ yearly) and more severe drought conditions and provided the impacts of delaying the nuclear phase-out.

\section{Acknowledgments}

The authors are thankful to José Luis Velasco for downloading and formatting the historical time series on electricity generation and demand from REE website. We also thank Rodrigo Moretón who converted the irradiance time series into PV output for different locations across Spain. They were later used to obtain aggregate PV hourly capacity factors representative for peninsular Spain. This work has benefited from multiple fruitful discussions and suggestions from several members of the Energy Critical Observatory to whom the authors are really grateful. The authors also thank Martin Greiner for helpful discussions and suggestions. Marta Victoria is partially funded by the RE-INVEST project (Renewable Energy Investment Strategies. A twodimensional interconnectivity approach), which is supported by the Innovation Fund Denmark under Grant No. 6154-00022B.

\section{Appendix A. Supplementary material}

Supplementary data associated with this article can be found, in the online version, at https://doi.org/10.1016/j.apenergy.2018.10.055.

\section{References}

[1] Rogelj J, Luderer G, Pietzcker RC, Kriegler E, Schaeffer M, Krey V, et al. Energy system transformations for limiting end-of-century warming to below $1.5^{\circ} \mathrm{C}$. Nat Clim Change 2015;5(6):519-27. https://doi.org/10.1038/nclimate2572<http:// www.nature.com/nclimate/journal/v5/n6/full/nclimate2572.html $>$.

[2] Energy [r] evolution. Tech. rep. Greenpeace Int; 2012.

[3] The energy report: 100\% renewable energy by 2050. Tech. rep. WWF; 2011.

[4] Pathways to a clean energy system. Tech. rep. International Energy Agency; 2012.

[5] Brancucci Martínez-Anido C, Vandenbergh M, de Vries L, Alecu C, Purvins A, Fulli $\mathrm{G}$, et al. Medium-term demand for European cross-border electricity transmission capacity. Energy Policy 2013;61:207-22. https://doi.org/10.1016/j.enpol.2013.05. $073<\mathrm{http}: /$ www.sciencedirect.com/science/article/pii/S0301421513004254>.

[6] Eriksen EH, Schwenk-Nebbe LJ, Tranberg B, Brown T, Greiner M. Optimal heterogeneity in a simplified highly renewable European electricity system. Energy 2017;133(Suppl. C):913-28. https://dol.org/10.1016/i.energy.2017.05. $170<\mathrm{http} / /$ www.sciencedirect.com/science/article/pii/S0360544217309593>.

[7] Schlachtberger DP, Brown T, Schramm S, Greiner M. The benefits of cooperation in a highly renewable European electricity network. Energy 2017;134(Suppl. C):469-81. https://doi.org/10.1016/j.energy.2017.06.004<http://www. sciencedirect.com/science/article/pii/S0360544217309969>.

[8] Jacobson MZ, Delucchi MA, Cameron MA, Frew BA. Low-cost solution to the grid reliability problem with $100 \%$ penetration of intermittent wind, water, and solar for all purposes. Proc Natl Acad Sci 2015;112(49):15060-5. https://doi.org/10.1073/ pnas. $1510028112<\mathrm{http} / /$ www.pnas.org/content/112/49/15060 $>$.

[9] Lund H, Mathiesen BV. Energy system analysis of $100 \%$ renewable energy systems. The case of Denmark in years 2030 and 2050. Energy 2009;34(5):524-31. https:// doi.org/10.1016/j.energy.2008.04.003<http://www.sciencedirect.com/science/ article/pii/S0360544208000959>.

[10] Elliston B, Diesendorf M, MacGill I. Simulations of scenarios with $100 \%$ renewable electricity in the Australian National Electricity Market. Energy Policy 2012;45:606-13. https://doi.org/10.1016/j.enpol.2012.03.011<http://www. sciencedirect.com/science/article/pii/S0301421512002169>.

[11] Mason IG, Page SC, Williamson AG. A 100\% renewable electricity generation system for New Zealand utilising hydro, wind, geothermal and biomass resources. Energy Policy 2010;38(8):3973-84. https://doi.org/10.1016/j.enpol.2010.03. 022<http://www.sciencedirect.com/science/article/pii/S0301421510001850 >

[12] Krajačić G, Duić N, Carvalho MdG. How to achieve a 100\% RES electricity supply for Portugal? Appl Energy 2011;88(2):508-17. https://doi.org/10.1016/j. apenergy. 2010.09.006 <http://www.sciencedirect.com/science/article/pii/ S0306261910003703>.

[13] Vers un mix électrique $100 \%$ renouvelable en 2050 . Tech. rep. Agence de l'Environnement et de la Maîtrise de l'énergie (ADEME); 2013.

[14] Connolly D, Lund H, Mathiesen BV, Leahy M. The first step towards a $100 \%$ renewable energy-system for Ireland. Appl Energy 2011;88(2):502-7. https://doi. org/10.1016/j.apenergy.2010.03.006<http://www.sciencedirect.com/science/ article/pii/S030626191000070X >

[15] Pathways towards a 100\% renewable electricity system. Tech. rep. Germany Advisory Council on the Environment; 2011.

[16] Olauson J, Ayob MN, Bergkvist M, Carpman N, Castellucci V, Goude A, et al. Net load variability in Nordic countries with a highly or fully renewable power system. Nat Energy 1(12). https://doi.org/10.1038/nenergy.2016.175. < https://www. nature.com/articles/nenergy2016175 > .

[17] Jacobson MZ, Delucchi MA. Providing all global energy with wind, water, and solar power, Part I: Technologies, energy resources, quantities and areas of infrastructure, and materials. Energy Policy 2011;39(3):1154-69. https://doi.org/10. 1016/j.enpol.2010.11.040<http://www.sciencedirect.com/science/article/pii/ S0301421510008645>

[18] Energía 3.0. Tech. rep. Greenpeace; 2011.

[19] Jacobson MZ. $100 \%$ clean and renewable wind, water, and sunlight all-sector energy roadmaps for 139 countries of the World. Joule 2017;1(1):108-21. https://doi. org/10.1016/j.joule.2017.07.005 < http://www.sciencedirect.com/science/ article/pii/S2542435117300120>.

[20] Renovables $100 \%$. Un sistema eléctrico renovable para la España peninsular y su viabilidad económica. Tech. rep. Greenpeace; 2007.

[21] Galbete S. Viabilidad técnico-económica para un suministro eléctrico 100\% renovable en España (Ph.D. thesis). Universidad Pública de Navarra; 2013.

[22] Zubi G, Bernal-Agustn JL, Fandos Marn AB. Wind energy (30\%) in the Spanish power mix. Technically feasible and economically reasonable. Energy Policy 2009;37 (8):3221-6. https://doi.org/10.1016/j.enpol.2009.04.012<http://www. sciencedirect.com/science/article/pii/S0301421509002638>.

[23] Cochran J, Mai T, Bazilian M. Meta-analysis of high penetration renewable energy scenarios. Renew Sustain Energy Rev 2014;29:246-53. https://doi.org/10.1016/j. rser.2013.08.089<http://www.sciencedirect.com/science/article/pii/ $S 1364032113006291>$.

[24] Renovables 2050. Un informe sobre el potencial de las energías renovables en la España peninsular. Tech. rep. Greenpeace; 2005.

[25] Thomaidis NS, Santos-Alamillos FJ, Pozo-Vzquez D, Usaola-Garca J. Optimal management of wind and solar energy resources. Comput Oper Res 2016;66(C):284-91. https://doi.org/10.1016/j.cor.2015.02.016.

[26] Breyer C, Bogdanov D, Gulagi A, Aghahosseini A, Barbosa LS, Koskinen O, et al. On the role of solar photovoltaics in global energy transition scenarios. Prog Photovolt Res Appl 2017;25(8):727-45. https://doi.org/10.1002/pip.2885<http:// onlinelibrary.wiley.com/doi/10.1002/pip.2885/abstract > .

[27] Rasmussen MG, Andresen GB, Greiner M. Storage and balancing synergies in a fully or highly renewable pan-European power system. Energy Policy 2012;51:642-51. https://doi.org/10.1016/j.enpol.2012.09.009<http://www.sciencedirect.com/ science/article/pii/S0301421512007677>.

[28] Collins S, Deane P, Gallachir B, Pfenninger S, Staffell I. Impacts of inter-annual wind and solar variations on the European power system. Joule 1 . https://doi.org/10. 1016/j.joule.2018.06.020. < http://www.sciencedirect.com/science/article/pii/ $S 254243511830285 \mathrm{X}>$.

[29] Heard BP, Brook BW, Wigley TML, Bradshaw CJA. Burden of proof: a comprehensive review of the feasibility of $100 \%$ renewable-electricity systems. Renew Sustain Energy Rev 2017;76:1122-33. https://doi.org/10.1016/j.rser.2017.03. 114 < http://www.sciencedirect.com/science/article/pii/S1364032117304495>.

[30] Creutzig F, Agoston P, Goldschmidt JC, Luderer G, Nemet G, Pietzcker RC. The underestimated potential of solar energy to mitigate climate change. Nat Energy 2(9). https://doi.org/10.1038/nenergy.2017.140. < https://www.nature.com/ articles/nenergy $2017140>$

[31] El sistema eléctrico español. informe de red eléctrica España. Años 2016 y anteriores. Tech. rep. Red Eléctrica de España (REE).

[32] Andresen GB, Sondergaard AA, Greiner M. Validation of Danish wind time series from a new global renewable energy atlas for energy system analysis. Energy 2015;93(Part 1):1074-88. https://doi.org/10.1016/j.energy.2015.09.071<http// www.sciencedirect.com/science/article/pii/S0360544215012815>.

[33] http://eportal.magrama.gob.es/websiar/Inicio,aspx.

[34] http://vps156.cesvima.upm.es/sisifo/wordpress/?lang =es.

[35] Muñoz JL, Collares-Pereira M, Tyutyundzhiev N, Conlon M, Elmoussaoui A, Wilkin В. Ап open-source simulation tool of grid-connected PV systems. In: 28th European photovoltaic solar energy conference and exhibition; 2013. p. 3882-7. https://doi. org/10.4229/28thEUPVSEC2013-5BV.4.18. < http://www.eupvsec-proceedings. com/proceedings? paper $=22704>$. 
[36] Real Decreto 198/2015, de 23 de marzo, por el que se desarrolla el artículo 112 bis del texto refundido de la Ley de Aguas y se regula el canon por utilización de las aguas continentales para la producción de energía eléctrica en las demarcaciones intercomunitarias.

[37] Louwen A, van Sark W, Faaij A, Schropp R. Re-assessment of net energy production and greenhouse gas emissions avoidance after 40 years of photovoltaics development. Nat Commun 2016;7:13728. https://doi.org/10.1038/ncomms13728.

[38] Technical report on Member State results of the EUCO policy scenarios. Tech. rep.

[39] Snapshot of Global Photovoltaics Markets. Tech. rep. International Energy Agency; 2016.

[40] El carbón en España en 2016. Tech. rep. El Observatorio Crítico de la Energía; 2016. < http//observatoriocriticodelaenergia.org/wp-content/uploads/2016/09/ El_carbon_en_Espa\%C3\%B1a_en_2016.pdf $>$.

[41] Las trampas del carbón. Tech. rep. Greenpeace; 2015.

[42] Cabrera M, Vera A. Evaluación del potencial de energía de la biomasa. Tech. rep. DAE, Instituto para la diversificación y ahorro de la energía; 2011.

[43] Sexta Comunicación Nacional de España. Convención Marco de las Naciones Unidas sobre el Cambio Climático. Ministerio de Agricultura, Alimentación y Medio Ambiente. Tech. rep.; 2013.

[44] Bomann T, Staffell I. The shape of future electricity demand: exploring load curves in 2050s Germany and Britain. Energy 2015;90(Part 2):1317-33. https://doi.org/ 10.1016/j.energy.2015.06.082http://www.sciencedirect.com/science/article/pii/ S0360544215008385.

[45] Orths A, Eriksen P. The future has come: the $100 \%$ res driven power system is reality. Revue de IElectricité et de lElectronique 5. https://doi.org/10.23723/ 1301:2016-5/17783.

[46] Brown TW, Bischof-Niemz T, Blok K, Breyer C, Lund H, Mathiesen BV. Response to Burden of proof: a comprehensive review of the feasibility of $100 \%$ renewableelectricity systems. Renew Sustain Energy Rev 2018;92:834-47. https://doi.org/10. 1016/j.rser.2018.04.113http://www.sciencedirect.com/science/article/pii/ \$1364032118303307.

[47] Galbete S, Alonso O, Simón K. ¿Hacia un suministro eléctrico 100\% renovable en España? es posible, Era Solar 196.

[48] Low carbon jobs: The evidence for net job creation from policy support for energy efficiency and renewable energy. Tech. rep. UK Energy Research Centre; 2014.

[49] Schlachtberger DP, Brown T, Schäfer M, Schramm S, Greiner M. Cost optimal scenarios of a future highly renewable European electricity system: Exploring the influence of weather data, cost parameters and policy constraints. Energy 2018;163:100-14. https://doi.org/10.1016/j.energy.2018.08.070<http://www. sciencedirect.com/science/article/pii/S0360544218316025 > .

[50] Brown T, Schlachtberger D, Kies A, Schramm S, Greiner M. Synergies of sector coupling and transmission reinforcement in a cost-optimised, highly renewable European energy system. Energy 2018;160:720-39. https://doi.org/10.1016/j. energy.2018.06.222<http://www.sciencedirect.com/science/article/pii/ S036054421831288X>

[51] Gils HC, Scholz Y, Pregger T, Luca de Tena D, Heide D. Integrated modelling of variable renewable energy-based power supply in Europe. Energy 2017;123:173-88. https://doi.org/10.1016/j.energy.2017.01.115<http:/www. sciencedirect.com/science/article/pii/S0360544217301238>.

[52] Connolly D, Lund H, Mathiesen BV. Smart Energy Europe: the technical and economic impact of one potential $100 \%$ renewable energy scenario for the European Union. Renew Sustain Energy Rev 2016;60:1634-53. https://doi.org/10.1016/j. rser.2016.02.025<http://www.sciencedirect.com/science/article/pii/ S1364032116002331>.

[53] Sathaye J, Lucon O, Rahman A, Christensen F, Denton J, Fujino J, et al. Renewable energy in the context of sustainable energy. In: IPCC special report on renewable energy sources and climate change mitigation; 2011. 